\title{
An Understanding of the Global Status of Major Bacterial Pathogens of Milk Concerning Bovine Mastitis: A Systematic Review and Meta-Analysis (Scientometrics)
}

\author{
Paramanandham Krishnamoorthy ${ }^{1}$ (D), Kuralayanapalya P. Suresh ${ }^{1}$, Kavitha S. Jayamma ${ }^{1}$, Bibek R. Shome ${ }^{1}$, \\ Sharanagouda S. Patil ${ }^{1}$ and Raghavendra G. Amachawadi ${ }^{2, * D}$ \\ 1 Pathoepidemiology Laboratory, ICAR-National Institute of Veterinary Epidemiology and Disease \\ Informatics (NIVEDI), Post Box No. 6450, Ramagondanahalli, Yelahanka, Bengaluru 560064, India; \\ krishvet@gmail.com (P.K.); sureshkp97@rediffmail.com (K.P.S.); kavithaentomology@gmail.com (K.S.J.); \\ brshome@gmail.com (B.R.S.); sharanspin13@gmail.com (S.S.P.) \\ 2 Department of Clinical Sciences, College of Veterinary Medicine, Kansas State University, \\ Manhattan, KS 66506, USA \\ * Correspondence: agraghav@vet.ksu.edu
}

Citation: Krishnamoorthy, P.; Suresh K.P.; Jayamma, K.S.; Shome, B.R.; Patil, S.S.; Amachawadi, R.G. An Understanding of the Global Status of Major Bacterial Pathogens of Milk Concerning Bovine Mastitis: A Systematic Review and Meta-Analysis (Scientometrics) Pathogens 2021, 10, 545. https:// doi.org/10.3390/pathogens10050545

Academic Editor:

David Rodríguez-Lázaro

Received: 17 March 2021

Accepted: 28 April 2021

Published: 30 April 2021

Publisher's Note: MDPI stays neutral with regard to jurisdictional claims in published maps and institutional affiliations.

Copyright: (c) 2021 by the authors. Licensee MDPI, Basel, Switzerland. This article is an open access article distributed under the terms and conditions of the Creative Commons Attribution (CC BY) license (https:// creativecommons.org/licenses/by/ $4.0 /)$.
Abstract: In this study, the major mastitis pathogen prevalence in the cattle and buffalo of the world was estimated by a meta-analysis. Staphylococcus (S) species, Streptococcus (St) species, and Escherichia coli (Ec) prevalence studies reported during 1979-2019 were collected using online databases, and offline resources. A meta-analysis of these data was done with the meta package in R-Software. The Staphylococcus aureus was the major mastitis pathogen, mostly causing subclinical mastitis, Ec causing clinical mastitis and St causing subclinical and clinical mastitis. The pooled prevalence estimates of S, St, and Ec were 28\%,12\%, and 11\% in the world from 156, 129, and 92 studies, respectively. The S, St, and Ec prevalences were high in Latin America (51\%), Oceania (25\%), and Oceania (28\%), respectively. Higher S, St, and Ec prevalences were observed by molecular methods, signifying high sensitivity and usefulness for future studies. Among bacterial species, S. aureus (25\%) followed by coagulase-negative Staphylococcus species (20\%), Escherichia coli (11\%), St. agalactiae (9\%), St. uberis $(9 \%)$ were the important pathogens present in the milk of the world. We hypothesize that there is a urgent need to reduce mastitis pathogen prevalence by ensuring scientific farm management practices, proper feeding, therapeutic interventions to augment profits in dairying, and improving animal and human health.

Keywords: Staphylococcus species; Streptococcus species; Escherichia coli; prevalence; world; systematic review; meta-analysis

\section{Introduction}

Milk is considered to be a staple food for human beings throughout the world, and it also poses a public health risk only when consumed unpasteurized because it contains a high bacterial count and is a good medium for bacterial growth. Bovine mastitis, a centuryold production disease caused by various bacteriological agents, has been intensively monitored since 1917 [1]. Mastitis is a disease of dairy cows worldwide [2] and comprises different types, namely subclinical and clinical mastitis. It is caused by multi-etiological pathogens in that bacterial species are considered to be the most important causative agent that leads to milk production loss. Costello [3] found that the annual economic loss due to mastitis was estimated to be US\$200 per cow per year. The economic losses due to both subclinical and clinical mastitis are US\$98,228 million or 7165.51 crore Indian rupees annually in India, as reported in the literature [4]. A meta-analysis is an innovative tool for estimating the prevalence of various livestock diseases [5]. Lately, livestock disease prevalence estimates have been reported for subclinical and clinical mastitis, major mastitis pathogens in India [6], anaplasmosis in the world [7], and Staphylococcus aureus with 
methicillin-resistance in livestock in India [8]. The foremost reasons doing a meta-analysis is to sum up and amalgamate the results from a number of previous studies. It also aids in investigating the requirement of larger sample sizes, snowballing the accuracy in prevalence estimates, deciding whether new studies are required, and creating new hypotheses for future studies $[7,8]$. The important concepts to consider while doing a meta-analysis are the selection of studies, heterogeneity in reported prevalence values, and used data analysis methods [9].

The cattle and buffalo population in the world were 1489 and 206 million, respectively, in 2018, as reported by the Food and Agricultural Organization (FAO), Rome. The United States of America (USA) produced 82 million tons of cattle milk in 2018 and ranked first in the world, followed by India with 47 million tons; India ranked first in the total (cattle and buffalo) milk production in the world [10]. The per capita consumption of milk was highest in Belarus $(111.09 \mathrm{~kg}$ ) in 2018 [11]. In the world, India ranks first for both buffalo milk production (55 million tons) and buffalo population. In 2018, Brazil had 193.5 million cattle, making it first ranked in the world, while India ranked second [10]. In India, the cattle and buffalo populations were 192.5 and 109.8 million, respectively, out of a total livestock population of 535.8 million in 2019, as reported in the 20th Livestock Census report. In 2019, the per capita availability of milk was 394 grams per day, and 187.75 million tons comprised the total milk production, as reported by the Ministry of Fisheries, Animal Husbandry, and Dairying, Government of India, New Delhi [12]. The major pathogens causing mastitis could be attributed to Staphylococcus aureus, Streptococcus agalactiae, Corynebacterium bovis, Mycoplasma species, Streptococcus uberis [13], coliforms (Escherichia coli, Klebsiella species, and Enterobacter aerogenes), Serratia, Pseudomonas, Proteus species, environmental Streptococci, and Enterobacter species (as described earlier) [14]. Amongst the bacterial species, Staphylococcus (S), Streptococcus (St), and Escherichia coli (Ec) have been deemed as the major mastitis pathogens in dairy cattle and buffalo. Numerous studies are available on $S$, St, and Ec prevalence in the milk of cattle and buffalo reported from various geographical locations in several countries of the world, which have indicated highly conflicting results regarding the major mastitis pathogen prevalences. Our previous study analyzed and reported the major mastitis pathogen prevalences in India from 1995 to 2016 by using a meta-analysis [6]. However, there have been no studies on the prevalence status of three major mastitis pathogens in the world. Keeping that in mind, the present study was undertaken to identify the highly important mastitis pathogens and their prevalence status among the three major mastitis pathogen groups in the milk of cattle and buffalo in the world by using systematic review and a meta-analysis.

\section{Results}

\subsection{Staphylococcus (S) Species, Streptococcus (St) Species, and Escherichia coli (Ec)} Prevalence Studies

The systematic review and meta-analysis of S, St, and Ec prevalence studies in cattle and buffalo from the world were undertaken in the present study. The filled-in PRISMA checklist for systematic review and meta-analysis is given in Supplementary File S1. The number of studies on S, St, and Ec prevalence in milk for the world included for metaanalysis were 156,129, and 92, respectively, and they included studies from all continents except for Antarctica. The details of the studies regarding the continents of the world; countries; author name; year; type of mastitis; reported prevalence of S, St, or Ec; and quality assessment scores are given in Table 1. The number of countries included for determining S, St, and Ec prevalence estimates were 49, 45, and 34, respectively. There were more prevalence studies from Europe (16) than from Oceania (2). There were more prevalence studies for $S$. aureus (137) and St. agalactiae (83) than the other bacterial species. The number of studies reported based on year and country for the world is given in Figure 1. The S, St, and Ec prevalence studies reported during the periods of 1979-2019, 1979-2019, and 1996-2019, respectively, from the world were included for meta-analysis. The increased number of studies reported were $23(\mathrm{~S}), 18(\mathrm{St})$, and $18(\mathrm{Ec})$ during the year 2013. Ethiopia reported the highest number of studies on S, St, and Ec prevalence, with 
36, 33, and 24 studies, respectively. The S, St, and Ec prevalence studies from India were analyzed separately, as mentioned earlier, and an attempt was made as an example for better understanding.
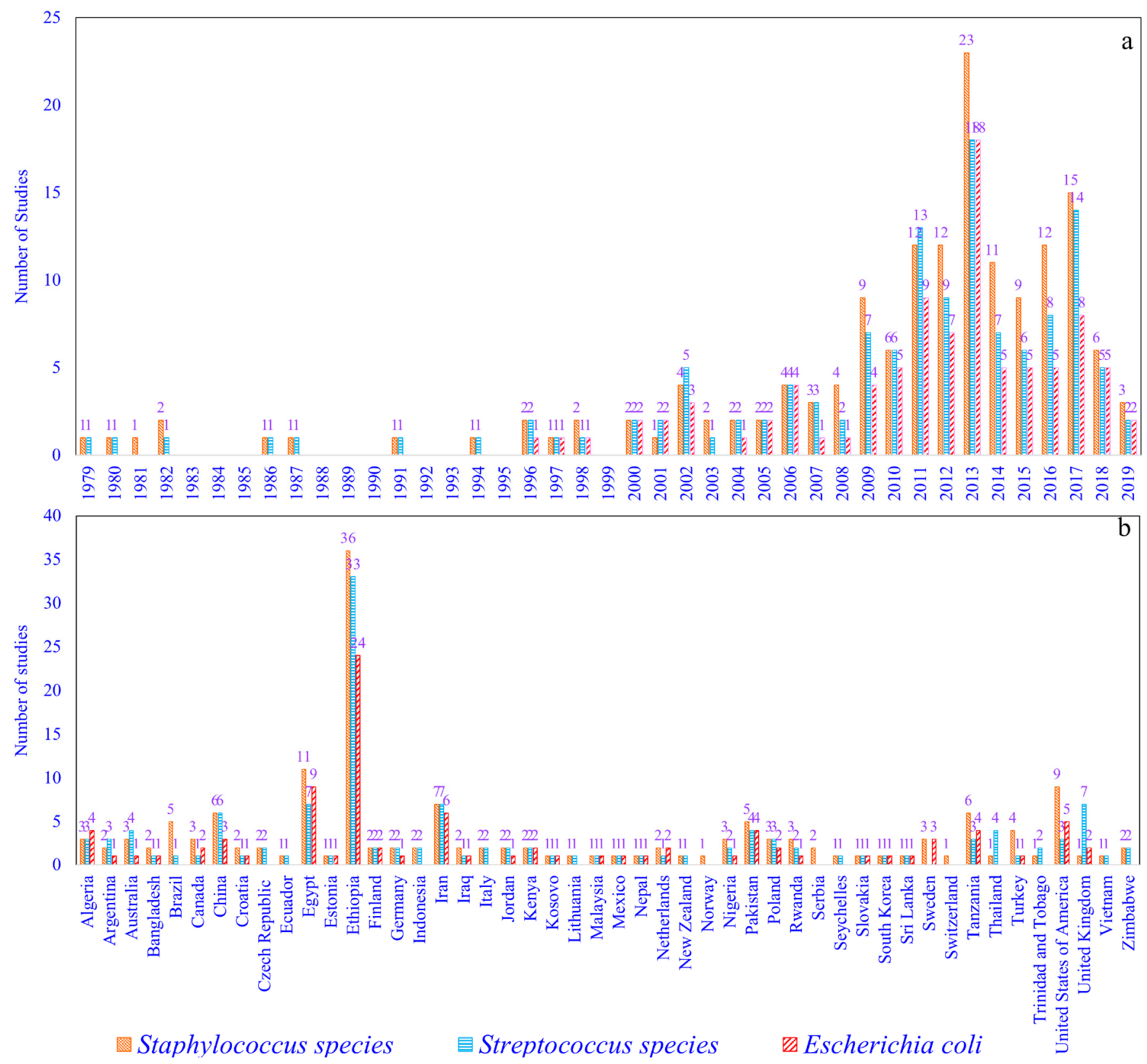

Figure 1. Year-wise (a) and country-wise (b) number of prevalence studies from the world included for meta-analysis. 
Table 1. Particulars of major mastitis pathogen prevalence studies from the world, with their quality assessment scores, included for a meta-analysis.

\begin{tabular}{|c|c|c|c|c|c|c|c|c|c|c|c|}
\hline \multirow[b]{2}{*}{ No. } & \multirow[b]{2}{*}{ Continents } & \multirow[b]{2}{*}{ Countries } & \multirow[b]{2}{*}{ Studies (Author and Year) } & \multirow[b]{2}{*}{ SCM-1, CM-2, M-3 } & \multirow[b]{2}{*}{ S.-1, St.-2, Ec-3 } & \multicolumn{6}{|c|}{ Quality Assessment of the Studies \# } \\
\hline & & & & & & $\begin{array}{c}\text { Sample } \\
\text { Representation } \\
\text { (Maximum } \\
\text { Score = 2) }\end{array}$ & $\begin{array}{l}\text { Size of Sample } \\
\text { (Maximum } \\
\text { Score = 2) }\end{array}$ & $\begin{array}{l}\text { Methods } \\
\text { Employed } \\
\text { (Maximum } \\
\text { Score = 2) }\end{array}$ & $\begin{array}{l}\text { Prevalence } \\
\text { Values } \\
\text { (Maximum } \\
\text { Score = 2) }\end{array}$ & $\begin{array}{l}\text { Assessment of } \\
\text { Outcome } \\
\text { (Maximum } \\
\text { Score = 2) }\end{array}$ & $\begin{array}{l}\text { Total Score } \\
\text { (Maximum } \\
\text { Score = 10) }\end{array}$ \\
\hline 1. & \multirow{25}{*}{ Africa } & \multirow{4}{*}{ Algeria } & Akkou et al., 2018 & 3 & 1 & ** & $* *$ & * & ** & * & 8 \\
\hline 2. & & & Bakir et al., 2011 & 1 & $1,2,3$ & $*$ & * & * & * & * & 5 \\
\hline 3. & & & Benhamed et al., 2011 & 3 & $1,2,3$ & ** & * & * & ** & * & 7 \\
\hline 4. & & & Saidi et al., 2013 & 3 & $1,2,3$ & $* *$ & $* *$ & * & $* *$ & * & 8 \\
\hline 5. & & \multirow{13}{*}{ Egypt } & Abdel-Rady and Sayed, 2009 & 1 & $1,2,3$ & ** & ** & * & ** & * & 8 \\
\hline 6. & & & Abd-Elrahman, 2013 & 3 & $1,2,3$ & $*$ & * & * & $* *$ & * & 6 \\
\hline 7. & & & Abo-Shama, 2014 & 3 & 1 & $* *$ & $* *$ & $* *$ & ** & * & 9 \\
\hline 8. & & & Ahmed et al., 2018 & 1 & 3 & ** & $* *$ & $* *$ & ** & * & 9 \\
\hline 9. & & & Amin et al., 2011 & 3 & $1,2,3$ & $* *$ & $* *$ & $* *$ & $* *$ & * & 9 \\
\hline 10. & & & El-Jakee et al., 2013 & 3 & 1 & $* *$ & $* *$ & $* *$ & $* *$ & * & 9 \\
\hline 11. & & & Elbably et al., 2013 & 3 & 1,3 & ** & $* *$ & $*$ & $* *$ & * & 8 \\
\hline 12. & & & Elhaig and Selim, 2014 & 1 & 1,2 & ** & ** & $* *$ & ** & * & 9 \\
\hline 13. & & & Elsayed et al., 2015 & 3 & 1 & ** & ** & $* *$ & ** & * & 9 \\
\hline 14. & & & Hamed and Zaitoun,2014 & 1 & $1,2,3$ & ** & $* *$ & $* *$ & ** & * & 9 \\
\hline 15. & & & Lamey et al., 2013 & 3 & 3 & * & * & $*$ & $* *$ & * & 6 \\
\hline 16. & & & Sayed et al., 2014 & 3 & $1,2,3$ & * & * & $*$ & $* *$ & * & 6 \\
\hline 17. & & & Zaki et al., 2010 & 1 & $1,2,3$ & $* *$ & $* *$ & $*$ & $* *$ & * & 8 \\
\hline 18. & & \multirow{8}{*}{ Ethiopia } & Abebe et al., 2012 & 3 & $1,2,3$ & ** & $* *$ & * & $* *$ & * & 8 \\
\hline 19. & & & Abebe et al., 2016 & 3 & 1 & $* *$ & $* *$ & * & $* *$ & * & 8 \\
\hline 20. & & & Abera et al., 2013 & 3 & $1,2,3$ & ** & ** & * & $* *$ & * & 8 \\
\hline 21. & & & Abunna et al., 2013 & 3 & $1,2,3$ & $* *$ & $* *$ & * & $* *$ & * & 8 \\
\hline 22. & & & Adane et al., 2012 & 3 & $1,2,3$ & $* *$ & $* *$ & * & $* *$ & * & 8 \\
\hline 23. & & & Amin et al., 2017 & 3 & 2 & $* *$ & $* *$ & * & $* *$ & * & 8 \\
\hline 24. & & & Ayano et al., 2013 & 1 & $1,2,3$ & $* *$ & $* *$ & $*$ & ** & $*$ & 8 \\
\hline 25. & & & Belayneh et al., 2013 & 3 & $1,2,3$ & ** & ** & * & $* *$ & * & 8 \\
\hline
\end{tabular}


Table 1. Cont.

\begin{tabular}{|c|c|c|c|c|c|c|c|c|c|c|c|}
\hline \multirow[b]{2}{*}{ No. } & \multirow[b]{2}{*}{ Continents } & \multirow[b]{2}{*}{ Countries } & \multirow[b]{2}{*}{ Studies (Author and Year) } & \multirow[b]{2}{*}{ SCM-1, CM-2, M-3 } & \multirow[b]{2}{*}{ S.-1, St.-2, Ec-3 } & \multicolumn{6}{|c|}{ Quality Assessment of the Studies \# } \\
\hline & & & & & & $\begin{array}{c}\text { Sample } \\
\text { Representation } \\
\text { (Maximum } \\
\text { Score = 2) }\end{array}$ & $\begin{array}{l}\text { Size of Sample } \\
\text { (Maximum } \\
\text { Score = 2) }\end{array}$ & $\begin{array}{l}\text { Methods } \\
\text { Employed } \\
\text { (Maximum } \\
\text { Score = 2) }\end{array}$ & $\begin{array}{l}\text { Prevalence } \\
\text { Values } \\
\text { (Maximum } \\
\text { Score = 2) }\end{array}$ & $\begin{array}{l}\text { Assessment of } \\
\text { Outcome } \\
\text { (Maximum } \\
\text { Score = 2) }\end{array}$ & $\begin{array}{l}\text { Total Score } \\
\text { (Maximum } \\
\text { Score = 10) }\end{array}$ \\
\hline 26. & & & Birhanu et al., 2017 & 1 & $1,2,3$ & $* *$ & $* *$ & * & $* *$ & * & 8 \\
\hline 27. & & & Dego and Tareke, 2003 & 3 & 1,2 & $* *$ & $*$ & $*$ & $* *$ & $*$ & 7 \\
\hline 28. & & & Demme and Abegaz, 2015 & 2 & $1,2,3$ & $*$ & * & $*$ & $* *$ & * & 6 \\
\hline 29. & & & Duguma et al., 2014 & 3 & 1,2 & $* *$ & * & * & ** & * & 7 \\
\hline 31. & & & Getahun et al., 2008 & 3 & 1,2 & ** & $* *$ & * & ** & $*$ & 8 \\
\hline 32. & & & Haftu et al., 2012 & 3 & $1,2,3$ & $* *$ & $* *$ & $*$ & $* *$ & $*$ & 8 \\
\hline 33. & & & Hailemeskel et al., 2014 & 3 & $1,2,3$ & $* *$ & $* *$ & * & $* *$ & * & 8 \\
\hline 34. & & & Kedir et al., 2016 & 3 & 1 & $* *$ & $* *$ & $*$ & *** & $*$ & 8 \\
\hline 35. & & & Lakew et al., 2009 & 3 & 1,2 & $* *$ & $* *$ & $*$ & ** & $*$ & 8 \\
\hline 36. & & & Megersa et al., 2012 & 3 & $1,2,3$ & $* *$ & $* *$ & $*$ & $* *$ & * & 8 \\
\hline 37. & & & Mekibib et al., 2010 & 3 & $1,2,3$ & $* *$ & $* *$ & * & ** & * & 8 \\
\hline 38. & & & Mekonnen and Tesfaye, 2010 & 3 & 1,2 & $* *$ & $* *$ & $*$ & $* *$ & * & 8 \\
\hline 40. & & & Mulate et al., 2017 & 1 & $1,2,3$ & $* *$ & $* *$ & $*$ & $* *$ & $*$ & 8 \\
\hline 41. & & & Pal et al., 2017 & 1 & $1,2,3$ & $* *$ & $*$ & * & $* *$ & $*$ & 7 \\
\hline 42. & & & Seid et al., 2015 & 3 & $1,2,3$ & $* *$ & $* *$ & * & ** & $*$ & 8 \\
\hline 43. & & & Shiferaw and Telila, 2016 & 3 & 1,2 & $* *$ & $* *$ & $*$ & $* *$ & * & 8 \\
\hline 44. & & & Sori et al., 2005 & 3 & $1,2,3$ & $*$ & * & * & ** & * & 6 \\
\hline 45. & & & Tadesse and Chanie, 2012 & 3 & $1,2,3$ & $* *$ & $* *$ & * & $* *$ & * & 8 \\
\hline 46. & & & Tekle and Berihe, 2015 & 3 & 1,3 & $* *$ & $* *$ & $*$ & $* *$ & $*$ & 8 \\
\hline 47. & & & Tesfaye and Albera, 2018 & 3 & $1,2,3$ & $* *$ & $* *$ & * & $* *$ & $*$ & 8 \\
\hline 48. & & & Tesfaye, 2017 & 3 & $1,2,3$ & $* *$ & $* *$ & * & $* *$ & * & 8 \\
\hline 49. & & & Wubishet et al., 2013 & 3 & 1,2 & $* *$ & $*$ & $*$ & $* *$ & $*$ & 7 \\
\hline 50. & & & Yohannes and Alemu, 2018 & 3 & $1,2,3$ & $* *$ & $* *$ & $*$ & ** & $*$ & 8 \\
\hline 51. & & & Yohannis and Molla, 2013 & 3 & $1,2,3$ & $* *$ & $* *$ & * & $* *$ & $*$ & 8 \\
\hline 52. & & & Zenebe et al., 2014 & 3 & $1,2,3$ & $* *$ & $* *$ & * & $* *$ & * & 8 \\
\hline 53. & & & Zeryehun and Abera, 2017 & 3 & 1,2 & $* *$ & $* *$ & * & ** & $*$ & 8 \\
\hline 54. & & & Zeryehun et al., 2013 & 3 & $1,2,3$ & $* *$ & $* *$ & * & ** & * & 8 \\
\hline
\end{tabular}


Table 1. Cont.

\begin{tabular}{|c|c|c|c|c|c|c|c|c|c|c|c|}
\hline \multirow[b]{2}{*}{ No. } & \multirow[b]{2}{*}{ Continents } & \multirow[b]{2}{*}{ Countries } & \multirow[b]{2}{*}{ Studies (Author and Year) } & \multirow[b]{2}{*}{ SCM-1, CM-2, M-3 } & \multirow[b]{2}{*}{ S.-1, St.-2, Ec-3 } & \multicolumn{6}{|c|}{ Quality Assessment of the Studies \# } \\
\hline & & & & & & $\begin{array}{c}\text { Sample } \\
\text { Representation } \\
\text { (Maximum } \\
\text { Score = 2) }\end{array}$ & $\begin{array}{l}\text { Size of Sample } \\
\text { (Maximum } \\
\text { Score = 2) }\end{array}$ & $\begin{array}{c}\text { Methods } \\
\text { Employed } \\
\text { (Maximum } \\
\text { Score = 2) }\end{array}$ & $\begin{array}{c}\begin{array}{c}\text { Prevalence } \\
\text { Values } \\
\text { (Maximum } \\
\text { Score = 2) }\end{array} \\
\end{array}$ & $\begin{array}{c}\text { Assessment of } \\
\text { Outcome } \\
\text { (Maximum } \\
\text { Score = 2) }\end{array}$ & $\begin{array}{l}\text { Total Score } \\
\text { (Maximum } \\
\text { Score = 10) }\end{array}$ \\
\hline 55. & & \multirow{2}{*}{ Kenya } & Mureithi et al., 2017 & 1 & $1,2,3$ & $* *$ & $*$ & * & $* *$ & $*$ & 7 \\
\hline 56. & & & Ondiek et al., 2013 & 1 & $1,2,3$ & $* *$ & $*$ & $*$ & $* *$ & $*$ & 7 \\
\hline 57. & & \multirow{4}{*}{ Nigeria } & Amosun et al., 2010 & 2 & 2 & * & $*$ & * & $* *$ & * & 6 \\
\hline 58. & & & Junaidu et al., 2011 & 3 & $1,2,3$ & $* *$ & $*$ & $*$ & $* *$ & $*$ & 7 \\
\hline 59. & & & Marimuthu et al., 2014 & 2 & 1 & $* *$ & ** & $*$ & $* *$ & $*$ & 8 \\
\hline 60. & & & Umaru et al., 2017 & 3 & 1 & $* *$ & $* *$ & * & $* *$ & $*$ & 8 \\
\hline 61. & & \multirow{3}{*}{ Rwanda } & Iraguha et al., 2015 & 1 & 1 & $* *$ & $* *$ & * & $* *$ & $*$ & 8 \\
\hline 62. & & & Mpatswenumugabo et al., 2017 & 1 & $1,2,3$ & $* *$ & $* *$ & * & $* *$ & $*$ & 8 \\
\hline 63. & & & Ndahetuye et al., 2019 & 1 & 1,2 & $* *$ & $* *$ & $*$ & $* *$ & $*$ & 8 \\
\hline 64. & & Seychelles & Watson et al., 1996 & 3 & 1,2 & $* *$ & $*$ & * & $* *$ & $*$ & 7 \\
\hline 65. & & \multirow{6}{*}{ Tanzania } & Kivaria et al., 2006 & 3 & $1,2,3$ & $* *$ & $* *$ & $*$ & $* *$ & $*$ & 8 \\
\hline 66. & & & Mdegela et al., 2004 & 3 & 1,2 & $* *$ & $* *$ & $*$ & $* *$ & $*$ & 8 \\
\hline 67. & & & Mdegela et al., 2009 & 3 & $1,2,3$ & $* *$ & $*$ & * & $* *$ & $*$ & 7 \\
\hline 68. & & & Motto et al., 2017 & 3 & 1 & $*$ & $*$ & * & $* *$ & $*$ & 6 \\
\hline 69. & & & Suleiman et al., 2013 & 1 & $1,2,3$ & $* *$ & $* *$ & $*$ & $* *$ & $*$ & 8 \\
\hline 70. & & & Suleiman et al., 2018 & 1 & 1,3 & $* *$ & $* *$ & * & $* *$ & * & 8 \\
\hline 71. & & \multirow{2}{*}{ Zimbabwe } & Kudinhaa and Simango, 2002 & 3 & 1 & ${ }^{*}$ & * & * & $* *$ & $*$ & 6 \\
\hline 72. & & & Perry et al., 1987 & 2 & 1,2 & $* *$ & $* *$ & $*$ & $* *$ & $*$ & 8 \\
\hline 73. & \multirow{9}{*}{ Asia } & \multirow{2}{*}{ Bangladesh } & Kayesh et al., 2014 & 1 & $1,2,3$ & $* *$ & $* *$ & $*$ & $* *$ & $*$ & 8 \\
\hline 74. & & & Islam et al., 2014 & 1 & 1 & $* *$ & $*$ & $* *$ & $* *$ & $*$ & 8 \\
\hline 75. & & \multirow{7}{*}{ China } & Bi et al., 2016 & 3 & $1,2,3$ & $* *$ & $* *$ & $* *$ & $* *$ & $*$ & 9 \\
\hline 76. & & & Cao et al., 2007 & 2 & 1,2 & $*$ & $*$ & $*$ & $* *$ & $*$ & 6 \\
\hline 77. & & & Cheng et al., 2019 & 2 & $1,2,3$ & $* *$ & $* *$ & $*$ & $* *$ & $*$ & 8 \\
\hline 78. & & & Gao et al., 2016 & 2 & $1,2,3$ & $* *$ & $*$ & $*$ & $* *$ & $*$ & 7 \\
\hline 79. & & & Li et al., 2009 & 1 & 1 & $* *$ & $* *$ & $*$ & $* *$ & $*$ & 8 \\
\hline 80. & & & Memon et al., 2012 & 3 & 1,2 & $* *$ & $* *$ & $* *$ & $* *$ & $*$ & 9 \\
\hline 81. & & & Zhang et al., 2017 & 2 & 2 & $*$ & ** & * & ** & $*$ & 7 \\
\hline
\end{tabular}


Table 1. Cont.

\begin{tabular}{|c|c|c|c|c|c|c|c|c|c|c|c|}
\hline \multirow[b]{2}{*}{ No. } & \multirow[b]{2}{*}{ Continents } & \multirow[b]{2}{*}{ Countries } & \multirow[b]{2}{*}{ Studies (Author and Year) } & \multirow[b]{2}{*}{ SCM-1, CM-2, M-3 } & \multirow[b]{2}{*}{ S.-1, St.-2, Ec-3 } & \multicolumn{6}{|c|}{ Quality Assessment of the Studies \# } \\
\hline & & & & & & $\begin{array}{c}\text { Sample } \\
\text { Representation } \\
\text { (Maximum } \\
\text { Score = 2) }\end{array}$ & $\begin{array}{l}\text { Size of Sample } \\
\text { (Maximum } \\
\text { Score = 2) }\end{array}$ & $\begin{array}{c}\text { Methods } \\
\text { Employed } \\
\text { (Maximum } \\
\text { Score = 2) }\end{array}$ & $\begin{array}{l}\text { Prevalence } \\
\text { Values } \\
\text { (Maximum } \\
\text { Score = 2) }\end{array}$ & $\begin{array}{c}\text { Assessment of } \\
\text { Outcome } \\
\text { (Maximum } \\
\text { Score = 2) }\end{array}$ & $\begin{array}{l}\text { Total Score } \\
\text { (Maximum } \\
\text { Score = 10) }\end{array}$ \\
\hline 82. & & \multirow{2}{*}{ Indonesia } & Harjanti et al., 2018 & 1 & 1,2 & $*$ & $*$ & * & $* *$ & $*$ & 6 \\
\hline 83. & & & Lucia et al., 2017 & 1 & 1,2 & $*$ & $*$ & $*$ & $* *$ & $*$ & 6 \\
\hline 84. & & \multirow{11}{*}{ Iran } & Atyabi et al., 2006 & 3 & $1,2,3$ & $* *$ & * & * & $* *$ & * & 7 \\
\hline 85. & & & Haghkhah et al., 2009 & 3 & 1,2 & * & $* *$ & * & $* *$ & * & 7 \\
\hline 86. & & & Haghkhah et al., 2011 & 1 & $1,2,3$ & $* *$ & ** & $*$ & $* *$ & $*$ & 8 \\
\hline 87. & & & Hashemi et al., 2011 & 3 & 2,3 & $* *$ & $* *$ & * & $* *$ & $*$ & 8 \\
\hline 88. & & & Jamali et al., 2014 & 2 & 1 & * & $*$ & * & $* *$ & $*$ & 6 \\
\hline 89. & & & Kalantari et al., 2013 & 1 & $1,2,3$ & $* *$ & $* *$ & * & $* *$ & $*$ & 8 \\
\hline 90. & & & Marashifard et al., 2019 & 1 & 3 & $* *$ & $*$ & $*$ & $* *$ & $*$ & 7 \\
\hline 91. & & & Moatamedi et al., 2007 & 1 & 2 & $*$ & $*$ & $* *$ & $* *$ & $*$ & 7 \\
\hline 92. & & & Momtaz, 2010 & 3 & 3 & $* *$ & $* *$ & $*$ & $* *$ & $*$ & 8 \\
\hline 93. & & & Panahi and Saei, 2019 & 3 & 1 & $*$ & $* *$ & $*$ & $* *$ & $*$ & 7 \\
\hline 94. & & & Reza et al., 2011 & 3 & 1,2 & $* *$ & $* *$ & $*$ & $* *$ & $*$ & 8 \\
\hline 95. & & \multirow{2}{*}{ Iraq } & Abdulkadhim et al., 2012 & 1 & 1 & $* *$ & $* *$ & * & $* *$ & $*$ & 8 \\
\hline 96. & & & Hussein, 2012 & 1 & $1,2,3$ & $* *$ & $* *$ & $*$ & $* *$ & $*$ & 8 \\
\hline 97. & & \multirow{2}{*}{ Jordan } & Alekish, 2015 & 1 & $1,2,3$ & $* *$ & $* *$ & * & $* *$ & $*$ & 8 \\
\hline 98. & & & Lafi et al., 1994 & 3 & 1,2 & $* *$ & ** & * & $* *$ & $*$ & 8 \\
\hline 99. & & Malaysia & Othman and Bahaman, 2005 & 1 & $1,2,3$ & $* *$ & $*$ & $*$ & $* *$ & $*$ & 7 \\
\hline 100. & & Nepal & Shrestha and Bindari, 2012 & 1 & $1,2,3$ & $* *$ & $* *$ & $*$ & $* *$ & $*$ & 8 \\
\hline 101. & & \multirow{5}{*}{ Pakistan } & Ali et al., 2011 & 1 & $1,2,3$ & $* *$ & $* *$ & $*$ & $* *$ & $*$ & 8 \\
\hline 102. & & & Baloch et al., 2013 & 2 & 1 & $*$ & * & * & $* *$ & * & 6 \\
\hline 103. & & & Farooq et al., 2008 & 3 & $1,2,3$ & $*$ & * & $*$ & $* *$ & $*$ & 6 \\
\hline 104. & & & Rafiullah et al., 2017 & 3 & 1,3 & $*$ & $* *$ & $*$ & $* *$ & $*$ & 7 \\
\hline 105. & & & Umar et al., 2013 & 3 & $1,2,3$ & $* *$ & $* *$ & $*$ & $* *$ & $*$ & 8 \\
\hline 106. & & South Korea & Nam et al., 2010 & 3 & $1,2,3$ & $* *$ & $* *$ & * & $* *$ & $*$ & 8 \\
\hline 107. & & Sri Lanka & Sanotharan et al., 2016 & 1 & $1,2,3$ & $* *$ & $* *$ & $*$ & $* *$ & $*$ & 8 \\
\hline 108. & & Thailand & Suriyasathaporn, 2011 & 1 & 1,2 & $*$ & ** & * & ** & $*$ & 7 \\
\hline
\end{tabular}


Table 1. Cont.

\begin{tabular}{|c|c|c|c|c|c|c|c|c|c|c|c|}
\hline \multirow[b]{2}{*}{ No. } & \multirow[b]{2}{*}{ Continents } & \multirow[b]{2}{*}{ Countries } & \multirow[b]{2}{*}{ Studies (Author and Year) } & \multirow[b]{2}{*}{ SCM-1, CM-2, M-3 } & \multirow[b]{2}{*}{ S.-1, St.-2, Ec-3 } & \multicolumn{6}{|c|}{ Quality Assessment of the Studies \# } \\
\hline & & & & & & $\begin{array}{c}\text { Sample } \\
\text { Representation } \\
\text { (Maximum } \\
\text { Score = 2) }\end{array}$ & $\begin{array}{l}\text { Size of Sample } \\
\text { (Maximum } \\
\text { Score = 2) }\end{array}$ & $\begin{array}{c}\text { Methods } \\
\text { Employed } \\
\text { (Maximum } \\
\text { Score = 2) }\end{array}$ & $\begin{array}{l}\text { Prevalence } \\
\text { Values } \\
\text { (Maximum } \\
\text { Score = 2) }\end{array}$ & $\begin{array}{c}\text { Assessment of } \\
\text { Outcome } \\
\text { (Maximum } \\
\text { Score = 2) } \\
\end{array}$ & $\begin{array}{l}\text { Total Score } \\
\text { (Maximum } \\
\text { Score = 10) }\end{array}$ \\
\hline 109. & & \multirow{4}{*}{ Turkey } & Bal et al., 2010 & 1 & 1,2 & $*$ & $* *$ & * & $* *$ & $*$ & 7 \\
\hline 110. & & & Boynukara et al., 2008 & 1 & 1 & $*$ & $* *$ & * & $* *$ & $*$ & 7 \\
\hline 111. & & & Kirkan et al., 2003 & 3 & 1 & $*$ & * & * & $* *$ & $*$ & 6 \\
\hline 112. & & & Turutoglu et al., 2002 & 3 & $1,2,3$ & $*$ & ** & * & $* *$ & $*$ & 7 \\
\hline 113. & & Vietnam & Ostensson et al., 2013 & 1 & 1,2 & $* *$ & ** & * & $* *$ & $*$ & 8 \\
\hline 114. & \multirow{22}{*}{ Europe } & \multirow{2}{*}{ Croatia } & Macesic et al., 2012 & 3 & 1,3 & $* *$ & ** & * & $* *$ & * & 8 \\
\hline 115. & & & Macesic et al., 2016 & 1 & 1,2 & $* *$ & $* *$ & * & $* *$ & $*$ & 8 \\
\hline 116. & & \multirow{2}{*}{$\begin{array}{l}\text { Czech } \\
\text { Republic }\end{array}$} & Cervinkova et al., 2013 & 3 & 1,2 & $* *$ & ** & $* *$ & $* *$ & $*$ & 9 \\
\hline 117. & & & Vikova et al., 2017 & 2 & 1,2 & $* *$ & ** & $* *$ & $* *$ & $*$ & 9 \\
\hline 118. & & Estonia & Kalmus et al., 2006 & 2 & $1,2,3$ & ** & ** & * & $* *$ & $*$ & 8 \\
\hline 119. & & \multirow{2}{*}{ Finland } & Pyorala et al., 2011 & 3 & $1,2,3$ & $*$ & ** & * & $* *$ & $*$ & 7 \\
\hline 120. & & & Vakkamaki et al., 2017 & 3 & $1,2,3$ & * & * & $* *$ & $* *$ & * & 7 \\
\hline 121. & & \multirow{2}{*}{ Germany } & Edinger et al., 2000 & 2 & $1,2,3$ & $*$ & $*$ & $*$ & $* *$ & $*$ & 6 \\
\hline 122. & & & Soltau et al., 2016 & 2 & 1,2 & $* *$ & ** & * & $* *$ & $*$ & 8 \\
\hline 123. & & \multirow{2}{*}{ Italy } & Bortolami et al., 2015 & 1 & 1,2 & * & $*$ & * & $* *$ & $*$ & 6 \\
\hline 124. & & & Ceniti et al., 2017 & 2 & 1,2 & * & * & * & $* *$ & $*$ & 6 \\
\hline 125. & & Kosovo & Sylejmani et al., 2016 & 1 & $1,2,3$ & ** & ** & * & $* *$ & * & 8 \\
\hline 126. & & Lithuania & Klimiene et al., 2011 & 3 & 1,2 & ** & ** & * & $* *$ & * & 8 \\
\hline 127. & & \multirow{3}{*}{ Netherlands } & Doofer et al., 1998 & 2 & 3 & $* *$ & ** & $* *$ & $* *$ & $*$ & 9 \\
\hline 128. & & & Miltenburg et al., 1996 & 2 & 1,2 & $* *$ & ** & * & $* *$ & * & 8 \\
\hline 129. & & & Swinkels et al., 2013 & 2 & 1 & * & $*$ & * & $* *$ & * & 6 \\
\hline 130. & & Norway & Bakken,1981 & 1 & 1 & $* *$ & ** & * & $* *$ & $*$ & 8 \\
\hline 131. & & \multirow{3}{*}{ Poland } & Hameed et al., 2006 & 3 & $1,2,3$ & * & * & * & $* *$ & * & 6 \\
\hline 132. & & & Krukowski et al., 2000 & 3 & $1,2,3$ & $*$ & ** & * & $* *$ & * & 7 \\
\hline 133. & & & Szczubial et al., 2012 & 1 & 1,2 & $*$ & $*$ & * & $* *$ & $*$ & 6 \\
\hline 134. & & \multirow{2}{*}{ Serbia } & Marija et al., 2016 & 3 & 1 & $* *$ & $*$ & * & $* *$ & $*$ & 7 \\
\hline 135. & & & Zutic et al., 2012 & 1 & 1 & ** & ** & * & $* *$ & * & 8 \\
\hline
\end{tabular}


Table 1. Cont.

\begin{tabular}{|c|c|c|c|c|c|c|c|c|c|c|c|}
\hline \multirow[b]{2}{*}{ No. } & \multirow[b]{2}{*}{ Continents } & \multirow[b]{2}{*}{ Countries } & \multirow[b]{2}{*}{ Studies (Author and Year) } & \multirow[b]{2}{*}{ SCM-1, CM-2, M-3 } & \multirow[b]{2}{*}{ S.-1, St.-2, Ec-3 } & \multicolumn{6}{|c|}{ Quality Assessment of the Studies \# } \\
\hline & & & & & & $\begin{array}{c}\text { Sample } \\
\text { Representation } \\
\text { (Maximum } \\
\text { Score = 2) }\end{array}$ & $\begin{array}{l}\text { Size of Sample } \\
\text { (Maximum } \\
\text { Score = 2) }\end{array}$ & $\begin{array}{c}\text { Methods } \\
\text { Employed } \\
\text { (Maximum } \\
\text { Score = 2) }\end{array}$ & $\begin{array}{l}\text { Prevalence } \\
\text { Values } \\
\text { (Maximum } \\
\text { Score = 2) }\end{array}$ & $\begin{array}{c}\text { Assessment of } \\
\text { Outcome } \\
\text { (Maximum } \\
\text { Score = 2) }\end{array}$ & $\begin{array}{l}\text { Total Score } \\
\text { (Maximum } \\
\text { Score = 10) }\end{array}$ \\
\hline 136. & & Slovakia & Idriss et al., 2013 & 2 & $1,2,3$ & $* *$ & $*$ & * & $* *$ & $*$ & 7 \\
\hline 137. & & \multirow{3}{*}{ Sweden } & Bengtsson et al., 2009 & 2 & $1,2,3$ & ** & ** & $*$ & ** & * & 8 \\
\hline 138. & & & Hangnestam et al., 2007 & 2 & $1,2,3$ & $* *$ & $* *$ & * & $* *$ & * & 8 \\
\hline 139. & & & Shitandi and Kihumbu, 2004 & 1 & $1,2,3$ & $* *$ & $* *$ & * & $* *$ & * & 8 \\
\hline 140. & & Switzerland & Graber et al., 2009 & 1 & 1 & $* *$ & $*$ & $*$ & $* *$ & * & 7 \\
\hline 141. & & \multirow{4}{*}{$\begin{array}{c}\text { United } \\
\text { Kingdom }\end{array}$} & Bradley and Green, 2001 & 2 & 3 & $* *$ & * & * & ** & * & 7 \\
\hline 142. & & & Breen et al., 2009 & 2 & 2,3 & $* *$ & $* *$ & $*$ & $* *$ & $*$ & 8 \\
\hline 143. & & & Davies et al., 2015 & 2 & 2 & $* *$ & $* *$ & $*$ & $* *$ & $*$ & 8 \\
\hline 144. & & & Milne et al., 2002 & 2 & 1,2 & $* *$ & $* *$ & $*$ & $* *$ & * & 8 \\
\hline 145. & \multirow{10}{*}{$\begin{array}{c}\text { Latin } \\
\text { America }\end{array}$} & \multirow{3}{*}{ Argentina } & Dieser et al., 2013 & 1 & $1,2,3$ & $* *$ & $* *$ & $*$ & $* *$ & * & 8 \\
\hline 146. & & & Gonzalez et al., 1980 & 1 & 1 & $* *$ & $* *$ & * & $* *$ & $*$ & 8 \\
\hline 147. & & & Lasango et al., 2011 & 1 & 2 & $* *$ & $* *$ & $*$ & $* *$ & $*$ & 8 \\
\hline 148. & & & Budri et al., 2015 & 1 & 1 & * & $*$ & * & $* *$ & $*$ & 6 \\
\hline 149. & & & Freitas et al., 2008 & 1 & 1 & $* *$ & $*$ & $*$ & $* *$ & $*$ & 7 \\
\hline 150. & & Brazil & Mesquita et al., 2018, & 3 & 1,2 & $* *$ & $* *$ & * & $* *$ & * & 8 \\
\hline 151. & & & Pardo et al., 2007 & 3 & 1 & $* *$ & $* *$ & $*$ & $* *$ & $*$ & 8 \\
\hline 152. & & & Silva et al., 2013 & 3 & 1 & $* *$ & $* *$ & $*$ & $* *$ & $*$ & 8 \\
\hline 153. & & Ecuador & Amer et al., 2018 & 3 & 1,2 & $* *$ & $* *$ & $*$ & $* *$ & $*$ & 8 \\
\hline 154. & & $\begin{array}{l}\text { Trinidad and } \\
\text { Tobago }\end{array}$ & Adesiyun et al., 1998 & 2 & 1 & $* *$ & $* *$ & * & $* *$ & * & 8 \\
\hline 155. & \multirow{9}{*}{$\begin{array}{c}\text { North } \\
\text { America }\end{array}$} & \multirow{4}{*}{ Canada } & Brooks et al., 1982 & 3 & 1,2 & $* *$ & $* *$ & $*$ & $* *$ & $*$ & 8 \\
\hline 156. & & & Condas et al., 2016 & 3 & 1 & $* *$ & $* *$ & ** & $* *$ & * & 9 \\
\hline 157. & & & Lago et al., 2010 & 2 & 1,3 & $* *$ & $*$ & $*$ & $* *$ & $*$ & 7 \\
\hline 158. & & & Saini et al., 2013 & 3 & 3 & $* *$ & $* *$ & $*$ & $* *$ & $*$ & 8 \\
\hline 159. & & Mexico & Leon-Galvan et al., 2015 & 3 & $1,2,3$ & $* *$ & $*$ & $* *$ & $* *$ & * & 8 \\
\hline 160. & & \multirow{4}{*}{$\begin{array}{l}\text { United States } \\
\text { of America }\end{array}$} & Anderson et al., 2011 & 3 & 1 & $* *$ & $* *$ & * & $* *$ & * & 8 \\
\hline 161. & & & Erskine et al., 2002 & 2 & $1,2,3$ & $* *$ & $*$ & $*$ & $* *$ & $*$ & 7 \\
\hline 162. & & & Ganda et al., 2016 & 2 & $1,2,3$ & $*$ & $*$ & $* *$ & $* *$ & $*$ & 7 \\
\hline 163. & & & Gillespie et al., 2009 & 2 & 1 & $* *$ & $* *$ & * & $* *$ & $*$ & 8 \\
\hline
\end{tabular}


Table 1. Cont.

\begin{tabular}{|c|c|c|c|c|c|c|c|c|c|c|c|}
\hline \multirow[b]{2}{*}{ No. } & \multirow[b]{2}{*}{ Continents } & \multirow[b]{2}{*}{ Countries } & \multirow[b]{2}{*}{ Studies (Author and Year) } & \multirow[b]{2}{*}{ SCM-1, CM-2, M-3 } & \multirow[b]{2}{*}{ S.-1, St.-2, Ec-3 } & \multicolumn{6}{|c|}{ Quality Assessment of the Studies \# } \\
\hline & & & & & & $\begin{array}{c}\text { Sample } \\
\text { Representation } \\
\text { (Maximum } \\
\text { Score = 2) }\end{array}$ & $\begin{array}{l}\text { Size of Sample } \\
\text { (Maximum } \\
\text { Score = 2) }\end{array}$ & $\begin{array}{c}\text { Methods } \\
\text { Employed } \\
\text { (Maximum } \\
\text { Score = 2) }\end{array}$ & $\begin{array}{c}\text { Prevalence } \\
\text { Values } \\
\text { (Maximum } \\
\text { Score = 2) }\end{array}$ & $\begin{array}{c}\text { Assessment of } \\
\text { Outcome } \\
\text { (Maximum } \\
\text { Score = 2) }\end{array}$ & $\begin{array}{l}\text { Total Score } \\
\text { (Maximum } \\
\text { Score = 10) }\end{array}$ \\
\hline 165. & & & Morse et al., 1986 & 2 & 1 & * & $*$ & * & ** & $*$ & 6 \\
\hline 166. & & & Pankey et al., 1991 & 3 & 1,2 & *** & ** & $*$ & ** & $*$ & 8 \\
\hline 167. & & & Sargeant et al., 1998 & 2 & 1,2 & *** & ** & * & ** & * & 8 \\
\hline 168. & & & Schrick et al., 2001 & 1 & $1,2,3$ & $*$ & $*$ & $*$ & ** & * & 6 \\
\hline 169. & & & Wilson et al., 1997 & 3 & $1,2,3$ & ** & ** & * & ** & $*$ & 8 \\
\hline 170. & \multirow{5}{*}{ Oceania } & \multirow{4}{*}{ Australia } & Daniel et al., 1982 & 2 & 1,2 & $*$ & $*$ & * & ** & * & 6 \\
\hline 171. & & & Phuektes et al., 2001 & 2 & 2 & $*$ & $*$ & * & ** & * & 6 \\
\hline 172. & & & Plozza et al., 2011 & 1 & $1,2,3$ & $* *$ & ** & * & ** & $*$ & 8 \\
\hline 173. & & & Wanasinghe and Frost, 1979 & 1 & 1,2 & $* *$ & ** & * & $* *$ & * & 8 \\
\hline 174. & & New Zealand & Petrovski et al., 2009 & 2 & 1,2 & $* *$ & ** & * & ** & * & 8 \\
\hline
\end{tabular}

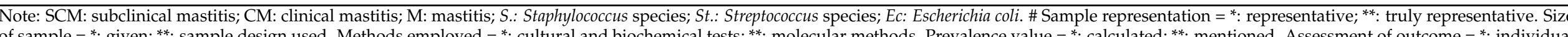

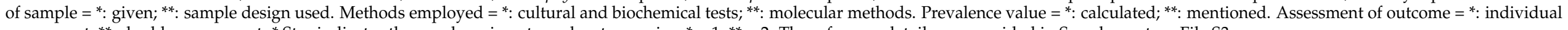
assessment; **: double assessment. ${ }^{*}$ Star indicates the number given to each category, i.e., ${ }^{*}=1 ;{ }^{* *}=2$. The reference details are provided in Supplementary File S3. 
The details of the meta-regression analysis of the different characteristics of S, St, and Ec prevalence studies are given in Table 2. The $S$ prevalence studies from the world revealed significant $(p<0.01)$ predictors as continents, methods used for identification, different bacterial species, countries, and St prevalence the year; methods and countries were highly $(p<0.01)$ significant. The methods used, host, and countries were revealed to be significant predictors for Ec prevalence estimates.

\subsection{Prevalence of $S, S t$, and Ec in the World}

The particulars of $S, S t$, and Ec prevalence in the world acquired by meta-analysis are shown in Tables 3-5, respectively. The pooled prevalence estimates for S, St, and Ec were $28 \%, 12 \%$, and $11 \%$, respectively, obtained from $283,685,272,539$, and 257,473 samples, respectively, from six continents of the world. The major mastitis pathogen prevalence appeared to be increasing in recent years, i.e., 2011-2019, in contrast to the past periods. Continent-wise S, St, and Ec prevalence estimates are depicted as a map in Figure 2. High S, St, and Ec prevalences were observed in Latin America (51\%), Oceania (28\%), and Oceania (25\%), respectively. The period-wise analysis revealed an increasing prevalence of $S$ in Africa, North America, Oceania, as well as a decreasing trend in Asia, Europe, and Latin America during the 2011-2019 period. St showed an increasing prevalence in recent times, i.e., 2011-2019. A higher Ec prevalence during 2011-2019 was observed in Africa and Asia, and a decreasing prevalence was found in Europe and North America. The S, St, and Ec prevalences found by molecular methods were $35 \%, 17 \%$, and $23 \%$, respectively. The bacterial species-wise analysis revealed a higher prevalence of $S$. aureus (25\%), followed by E. coli $(11 \%)$, S. epidermidis (9\%), St. agalactiae (9\%), and St. uberis (9\%). A higher prevalence of Staphylococcus species in subclinical mastitis, Streptococcus species in both forms of mastitis, and Escherichia coli in clinical mastitis were noticed. Regarding the test for publication bias, the $p$-value obtained for overall prevalence estimates for $S$, St, and Ec were $0.410,0.586$, and 0.219 , respectively, specifying that there was no bias among the prevalence studies. The Cochran $Q$ statistics showed highly significant $(p<0.01)$ differences between the studies included for $S, S t$, and Ec prevalence in the world sub-grouped based on year, continent, period, species, method, bacterial species, and type of mastitis, showing the heterogeneity between the studies selected for meta-analysis. There were few exceptions noticed, such as a significant $(p<0.05)$ difference for St. acidominimus and no significant difference for S. captis, S. cohni, S. kloosi, S. lentus, St. anginosus, St. bovis, St. intermedius, and St. mitis, as well as the North America period II for both in St and Ec that denoted no heterogeneity among the considered studies. 
Table 2. Details for the univariate meta-regression analysis of moderator variables in the major mastitis pathogen prevalence studies from the world.

\begin{tabular}{|c|c|c|c|c|c|c|c|c|c|c|}
\hline \multirow[b]{2}{*}{ No. } & \multirow[b]{2}{*}{ Predictors } & \multicolumn{3}{|c|}{ Model Results } & \multicolumn{4}{|c|}{ Mixed-Effects Model Results } & \multicolumn{2}{|c|}{ Test of Moderators } \\
\hline & & Estimate & Standard Error & Z Value (Test Statistic) & $\begin{array}{c}\text { Tau }^{2} \\
\text { (Estimated Residual } \\
\text { Heterogeneity) }\end{array}$ & $\begin{array}{l}\mathrm{I}^{2}(\%) \text { (Residual } \\
\text { Heterogeneity) }\end{array}$ & $\begin{array}{c}\mathbf{H}^{\mathbf{2}} \\
\text { (Sampling } \\
\text { Variability) }\end{array}$ & $\begin{array}{l}\mathbf{R}^{2}(\%) \text { (Amount } \\
\text { of Heterogeneity) }\end{array}$ & $\begin{array}{c}\text { QM } \\
\text { (Cochran Q Value for } \\
\text { Moderators) }\end{array}$ & $p$-Value \\
\hline \multicolumn{11}{|c|}{ Staphylococcus species } \\
\hline 1. & Year & -4.5307 & 3.7787 & -1.1990 & 0.0558 & 99.65 & 286.24 & 0.24 & 1.7404 & $0.1871^{\mathrm{NS}}$ \\
\hline 2. & Continents & 0.5320 & 0.2323 & 2.2907 & 0.0530 & 99.61 & 256.72 & 5.25 & 21.5992 & $0.0014^{* *}$ \\
\hline 3. & Sample size & 0.4544 & 0.0141 & 32.3310 & 0.0562 & 99.70 & 333.93 & 0.00 & 0.0028 & 0.9575 NS \\
\hline 4. & Methods & 0.4565 & 0.0149 & 30.3480 & 0.0508 & 99.60 & 249.05 & 9.23 & 31.6856 & $<0.0001^{* *}$ \\
\hline 6. & Host & 0.4889 & 0.0538 & 9.0841 & 0.0560 & 99.72 & 352.49 & 0.00 & 0.4434 & $0.5055^{\mathrm{NS}}$ \\
\hline 7. & Countries & 0.2778 & 0.0690 & 4.0253 & 0.0380 & 99.47 & 186.93 & 32.18 & 182.9442 & $<0.0001^{* *}$ \\
\hline \multicolumn{11}{|c|}{ Streptococcus species } \\
\hline 1. & Year & -5.7737 & 2.6655 & -2.1661 & 0.0287 & 99.36 & 155.48 & 1.60 & 5.2140 & $0.0224 *$ \\
\hline 2. & Continents & 0.3118 & 0.0172 & 18.1804 & 0.0294 & 99.32 & 147.40 & 0.00 & 3.2641 & $0.6593^{\mathrm{NS}}$ \\
\hline 3. & Sample size & 0.3130 & 0.0108 & 28.9534 & 0.0293 & 99.46 & 185.72 & 0.00 & 0.0422 & $0.8372 \mathrm{NS}$ \\
\hline 4. & Methods & 0.3071 & 0.0109 & 28.0433 & 0.0278 & 99.32 & 147.74 & 4.74 & 14.4731 & $0.0007^{* *}$ \\
\hline 7. & Countries & 0.2389 & 0.0680 & 3.5142 & 0.0258 & 99.26 & 134.96 & 11.41 & 75.6491 & $0.0015^{* *}$ \\
\hline \multicolumn{11}{|c|}{ Escherichia coli } \\
\hline 1. & Year & -7.502 & 7.3876 & -1.0179 & 0.0338 & 98.80 & 83.01 & 0.10 & 1.1417 & $0.2853^{\mathrm{NS}}$ \\
\hline 2. & Continents & 0.3747 & 0.0276 & 13.5921 & 0.0347 & 98.52 & 67.60 & 0.00 & 2.9948 & $0.7008^{\mathrm{NS}}$ \\
\hline 3. & Sample size & 0.3790 & 0.0192 & 19.6934 & 0.0331 & 99.49 & 195.72 & 2.41 & 3.0627 & $0.0801^{\mathrm{NS}}$ \\
\hline 4. & Methods & 0.3495 & 0.0192 & 18.2048 & 0.0298 & 98.75 & 80.19 & 12.01 & 13.3268 & $0.0003^{* *}$ \\
\hline 5. & Host & 0.5549 & 0.0765 & 7.2487 & 0.0322 & 99.54 & 215.90 & 4.95 & 5.9864 & 0.0144 * \\
\hline 6. & Countries & 0.4664 & 0.0929 & 5.0216 & 0.0283 & 97.10 & 34.45 & 16.33 & 50.2262 & $0.0212 *$ \\
\hline
\end{tabular}

Note: ${ }^{\text {NS: }}$ not significant; *: significant $(p<0.05)$; **: highly significant $(p<0.01)$. 
Table 3. Staphylococcus (S.) species prevalence estimates in the world based on various subgroup meta-analyses.

\begin{tabular}{|c|c|c|c|c|c|c|c|c|c|c|c|}
\hline \multirow[b]{2}{*}{ No. } & \multirow[b]{2}{*}{ Categories } & \multirow[b]{2}{*}{ Period } & \multirow[b]{2}{*}{$\begin{array}{l}\text { Number of } \\
\text { Studies }\end{array}$} & \multirow[b]{2}{*}{ Total Samples } & \multicolumn{2}{|c|}{ Pooled Estimates } & \multicolumn{5}{|c|}{ Tests of Heterogeneity } \\
\hline & & & & & $\begin{array}{c}\text { Prevalence (\%) [CI at 95\% } \\
\text { Level) }\end{array}$ & $\begin{array}{l}\text { PI (\%) at } 95 \% \\
\text { Level }\end{array}$ & $\mathrm{I}^{2}$ Value (\%) & $\begin{array}{l}\text { Tau Square } \\
\text { Value }\end{array}$ & H Value & $\begin{array}{l}\text { Degrees of } \\
\text { Freedom }\end{array}$ & $\underset{\text { Value }}{\text { Cochran } Q}$ \\
\hline 1. & World & 1979-2019 & 156 & 283,685 & $28(24-31)$ & $4-77$ & 99.6 & 1.165 & 14.98 & 155 & $38,800.6 * *$ \\
\hline \multicolumn{12}{|c|}{ Year-wise } \\
\hline 1. & World-I & 1979-2000 & 16 & 117,197 & $23(12-24)$ & $1-92$ & 99.8 & 2.797 & 24.30 & 15 & $2432.7^{* *}$ \\
\hline 2. & World-II & $2001-2010$ & 37 & 14,592 & $25(18-32)$ & $3-77$ & 98.7 & 1.296 & 8.79 & 36 & $1813.9^{* *}$ \\
\hline 3. & World-III & 2011-2019 & 103 & 151,896 & $30(26-34)$ & $6-73$ & 98.8 & 0.852 & 9.28 & 102 & $8720.9^{* *}$ \\
\hline \multicolumn{12}{|c|}{ Continent-wise } \\
\hline 1. & Africa & $1987-2019$ & 67 & 13,702 & $32(27-37)$ & $6-76$ & 97.3 & 0.934 & 6.06 & 66 & $2701.3^{* *}$ \\
\hline 2. & Asia & 1994-2019 & 36 & 13,396 & $27(21-34)$ & 5-74 & 98.2 & 0.964 & 7.49 & 35 & $1578.1^{* *}$ \\
\hline 3. & Europe & 1981-2017 & 27 & 131,152 & $23(17-29)$ & $4-67$ & 99.2 & 0.836 & 11.12 & 26 & $4228.9^{* *}$ \\
\hline 4. & Latin America & 1980-2018 & 9 & 2587 & $51(27-75)$ & $2-98$ & 98.9 & 2.491 & 9.69 & 8 & $805.5^{* *}$ \\
\hline 5. & North America & 1982-2016 & 13 & 116,927 & $13(8-20)$ & $2-57$ & 99.5 & 0.876 & 13.79 & 12 & $568.0^{* *}$ \\
\hline 6. & Oceania & 1979-2011 & 4 & 5921 & $31(16-50)$ & $1-96$ & 98.6 & 0.657 & 8.54 & 3 & $151.9^{* *}$ \\
\hline \multicolumn{12}{|c|}{ Period-wise } \\
\hline 1. & Africa-I & $1987-2010$ & 14 & 3108 & $24(12-43)$ & $1-92$ & 98.6 & 2.588 & 8.42 & 13 & $856.6^{* *}$ \\
\hline 2. & Africa-II & 2011-2019 & 53 & 10,594 & $34(30-38)$ & $11-68$ & 95.3 & 0.501 & 4.63 & 52 & $1018.6^{* *}$ \\
\hline 3. & Asia-I & 1994-2010 & 12 & 5410 & $28(21-36)$ & $8-62$ & 96.4 & 0.395 & 5.26 & 11 & $192.7^{* *}$ \\
\hline 4. & Asia-II & 2011-2019 & 24 & 7986 & $27(19-37)$ & $3-80$ & 98.2 & 1.282 & 7.50 & 23 & $1269.7^{* *}$ \\
\hline 5. & Europe-I & 1981-2009 & 11 & 6438 & $23(14-36)$ & $2-78$ & 98.9 & 1.115 & 9.41 & 10 & $708.0^{* *}$ \\
\hline 6. & Europe-II & 2011-2017 & 16 & 124,714 & $22(16-30)$ & $5-63$ & 98.9 & 0.655 & 9.58 & 15 & $2219.0^{* *}$ \\
\hline 7. & Latin America-I & 1980-2008 & 4 & 615 & $62(19-92)$ & $0-100$ & 98.5 & 3.959 & 8.11 & 3 & $373.8^{* *}$ \\
\hline 8. & Latin America-II & 2013-2018 & 5 & 1972 & $43(22-66)$ & $2-97$ & 98.3 & 1.143 & 7.69 & 4 & $369.1^{* *}$ \\
\hline 9. & North America-I & 1982-2009 & 9 & 110,401 & $12(7-21)$ & $1-59$ & 99.3 & 0.857 & 11.82 & 8 & $487.5^{* *}$ \\
\hline 10. & $\begin{array}{c}\text { North } \\
\text { America-II }\end{array}$ & 2011-2016 & 4 & 6526 & $16(7-32)$ & $0-95$ & 98.6 & 0.887 & 8.46 & 3 & $70.1^{* *}$ \\
\hline 11. & Oceania-I & 1979-2009 & 3 & 5817 & $23(14-35)$ & $0-100$ & 97.5 & 0.266 & 6.27 & 2 & $74.7^{* *}$ \\
\hline 12. & Oceania-II & 2011 & 1 & 104 & 60 & - & - & - & - & - & - \\
\hline \multicolumn{12}{|c|}{ Host species-wise } \\
\hline 1. & Cattle & 1979-2019 & 147 & 281,390 & $28(24-31)$ & $4-76$ & 99.6 & 1.163 & 15.27 & 146 & $38,517.2 * *$ \\
\hline 2. & Buffalo & 2008-2019 & 13 & 2255 & $31(20-46)$ & 4-84 & 96.9 & 1.131 & 5.71 & 12 & $291.7^{* *}$ \\
\hline
\end{tabular}


Table 3. Cont.

\begin{tabular}{|c|c|c|c|c|c|c|c|c|c|c|c|}
\hline \multirow[b]{2}{*}{ No. } & \multirow[b]{2}{*}{ Categories } & \multirow[b]{2}{*}{ Period } & \multirow{2}{*}{$\begin{array}{l}\text { Number of } \\
\text { Studies }\end{array}$} & \multirow[b]{2}{*}{ Total Samples } & \multicolumn{2}{|c|}{ Pooled Estimates } & \multicolumn{5}{|c|}{ Tests of Heterogeneity } \\
\hline & & & & & $\begin{array}{l}\text { Prevalence (\%) [CI at 95\% } \\
\text { Level) }\end{array}$ & $\begin{array}{l}\text { PI (\%) at } 95 \% \\
\text { Level }\end{array}$ & $\mathrm{I}^{2}$ Value (\%) & $\begin{array}{l}\text { Tau Square } \\
\text { Value }\end{array}$ & H Value & $\begin{array}{l}\text { Degrees of } \\
\text { Freedom }\end{array}$ & $\begin{array}{c}\text { Cochran } Q \\
\text { Value }\end{array}$ \\
\hline \multicolumn{12}{|c|}{ Method-wise } \\
\hline 1. & $\begin{array}{c}\text { Cultural } \\
\text { Examination }\end{array}$ & 1979-2019 & 132 & 154,085 & $27(23-31)$ & $4-77$ & 99.1 & 1.210 & 10.70 & 131 & $11,559.6 * *$ \\
\hline 2. & $\begin{array}{l}\text { Molecular } \\
\text { methods }\end{array}$ & 2008-2019 & 19 & 124,004 & $35(26-45)$ & $7-80$ & 99.0 & 0.874 & 10.11 & 18 & $1769.9^{* *}$ \\
\hline 3. & Other methods & 1980-2019 & 13 & 7989 & $22(16-29)$ & $5-58$ & 96.6 & 0.478 & 5.39 & 12 & $363.4^{* *}$ \\
\hline 1. & S. aureus & 1979-2019 & 137 & 273,336 & $25(21-29)$ & $3-76$ & 99.5 & 1.287 & 14.62 & 136 & $15,898.9^{* *}$ \\
\hline 2. & CNS & 1996-2017 & 18 & 123,118 & $20(14-28)$ & $3-65$ & 98.8 & 0.842 & 8.97 & 17 & $2022.0^{* *}$ \\
\hline 3. & S. auricularis & 2010 & 1 & 100 & 14 & - & - & - & - & - & - \\
\hline 4. & S. captis & 2010 and 2019 & 2 & 268 & $7(4-10)$ & - & 0.0 & 0.0 & 1.00 & 1 & $0.13^{\mathrm{NS}}$ \\
\hline 5. & S. caseolyticus & 2002 & 1 & 131 & 1.5 & - & - & - & - & - & - \\
\hline 6. & S. chromogenes & 2002-2019 & 9 & 6453 & $11(6-19)$ & $1-56$ & 97.1 & 0.866 & 5.82 & 8 & $170.7^{* *}$ \\
\hline 7. & S. cohnii & 2010 and 2015 & 2 & 136 & $4(2-9)$ & - & 0.0 & 0.0 & 1.00 & 1 & $0.45^{\mathrm{NS}}$ \\
\hline 8. & S. devriesei & 2019 & 1 & 168 & 1.6 & - & - & - & - & - & - \\
\hline 10. & S. haemolyticus & 2010-2019 & 3 & 5417 & $8(3-23)$ & $0-100$ & 96.5 & 1.047 & 5.32 & 2 & $77.4^{* *}$ \\
\hline 11. & S. hominis & & & & & & & & & & \\
\hline 12. & S. hyicus & 2002-2016 & 8 & 1991 & $6(3-12)$ & $1-39$ & 93.0 & 0.732 & 3.78 & 7 & $65.1^{* *}$ \\
\hline 13. & S. intermidius & 2004-2015 & 8 & 2808 & $4(2-8)$ & $1-26$ & 85.8 & 0.599 & 2.65 & 7 & $52.3^{* *}$ \\
\hline 14. & S. kloosii & 2002 and 2019 & 2 & 299 & $1(0-3)$ & - & 0.0 & 0.0 & 1.00 & 1 & $0.03^{\mathrm{NS}}$ \\
\hline 15. & S. lentus & 2002 and 2011 & 3 & 254 & $4(2-7)$ & $0-71$ & 0.0 & 0.0 & 1.00 & 2 & $0.98^{\mathrm{NS}}$ \\
\hline 16. & S. lugdunensis & 2019 & 1 & 168 & 0.6 & - & - & - & - & - & - \\
\hline 17. & S. muscae & 2019 & 1 & 131 & 0.8 & - & - & - & - & - & - \\
\hline 18. & S. pasteuri & 2019 & 1 & 168 & 2.4 & - & - & - & - & - & - \\
\hline 19. & S. saprophyticus & 2002-2019 & 5 & 1314 & $3(1-9)$ & $0-72$ & 86.3 & 1.586 & 2.70 & 4 & $39.6^{* *}$ \\
\hline 20. & S. sciuri & 2002-2019 & 4 & 608 & $4(1-14)$ & $0-94$ & 90.8 & 1.453 & 3.29 & 3 & $45.6^{* *}$ \\
\hline 21. & S. simulans & 2002-2018 & 7 & 6083 & $5(2-10)$ & $0-41$ & 92.5 & 0.882 & 3.65 & 6 & $55.1^{* *}$ \\
\hline 22. & S. warneri & 2010-2019 & 4 & 383 & $2(1-7)$ & $0-71$ & 56.9 & 0.826 & 1.52 & 3 & $11.65^{*}$ \\
\hline
\end{tabular}


Table 3. Cont.

\begin{tabular}{|c|c|c|c|c|c|c|c|c|c|c|c|}
\hline \multirow[b]{2}{*}{ No. } & \multirow[b]{2}{*}{ Categories } & \multirow[b]{2}{*}{ Period } & \multirow[b]{2}{*}{$\begin{array}{l}\text { Number of } \\
\text { Studies }\end{array}$} & \multirow[b]{2}{*}{ Total Samples } & \multicolumn{2}{|c|}{ Pooled Estimates } & \multicolumn{5}{|c|}{ Tests of Heterogeneity } \\
\hline & & & & & $\begin{array}{c}\text { Prevalence (\%) [CI at 95\% } \\
\text { Level) }\end{array}$ & $\begin{array}{l}\text { PI (\%) at } 95 \% \\
\text { Level }\end{array}$ & $\mathrm{I}^{2}$ Value (\%) & $\begin{array}{c}\text { Tau Square } \\
\text { Value }\end{array}$ & H Value & $\begin{array}{c}\text { Degrees of } \\
\text { Freedom }\end{array}$ & $\begin{array}{c}\text { Cochran } Q \\
\text { Value }\end{array}$ \\
\hline 23. & S. xylosus & 2002-2019 & 7 & 5896 & $5(3-10)$ & $1-30$ & 87.0 & 0.505 & 2.77 & 6 & $71.3^{* *}$ \\
\hline 24. & S. species & 1991-2018 & 34 & 119,139 & $25(18-35)$ & $2-83$ & 99.5 & 1.651 & 14.13 & 33 & $3280.5^{* *}$ \\
\hline \multicolumn{12}{|c|}{ Type of mastitis } \\
\hline 1. & Subclinical mastitis & 1979-2019 & 50 & 15,165 & $30(24-36)$ & $4-79$ & 98.3 & 1.176 & 7.69 & 49 & $20.2 .3^{* *}$ \\
\hline 2. & Clinical mastitis & 1982-2019 & 27 & 17,344 & $22(15-32)$ & $2-84$ & 99.3 & 1.878 & 12.15 & 26 & $2115.3^{* *}$ \\
\hline 3. & Mastitis & 1982-2019 & 79 & 251,176 & $29(25-33)$ & $6-73$ & 99.6 & 0.882 & 16.07 & 78 & $33,759.1$ ** \\
\hline
\end{tabular}

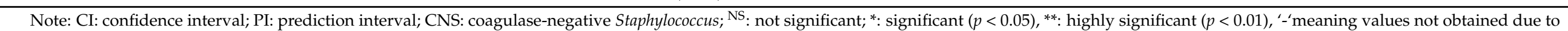
single study was available.

Table 4. Streptococcus (St.) species prevalence estimates in the world based on various subgroup meta-analyses.

\begin{tabular}{|c|c|c|c|c|c|c|c|c|c|c|c|}
\hline \multirow[b]{2}{*}{ No. } & \multirow[b]{2}{*}{ Categories } & \multirow[b]{2}{*}{ Period } & \multirow{2}{*}{$\begin{array}{c}\text { Number } \\
\text { of Studies }\end{array}$} & \multirow[b]{2}{*}{ Total Samples } & \multicolumn{2}{|c|}{ Pooled Estimates } & \multicolumn{5}{|c|}{ Tests of Heterogeneity } \\
\hline & & & & & $\begin{array}{c}\text { Prevalence (\%) [CI at } \\
95 \% \text { Level] }\end{array}$ & $\begin{array}{l}\text { PI (\%) at } 95 \% \\
\text { Level }\end{array}$ & $\mathrm{I}^{2}$ Value (\%) & Tau Square Value & H Value & Degrees of Freedom & Cochran $Q$ Value \\
\hline \multirow[t]{2}{*}{1.} & World & 1979-2019 & 129 & 272,539 & $12(10-14)$ & $2-54$ & 99.3 & 1.151 & 11.96 & 128 & $10,173.8^{* *}$ \\
\hline & & \multicolumn{10}{|c|}{ Year-wise } \\
\hline 1. & World-I & 1979-2000 & 13 & 116,643 & $7(5-11)$ & $1-34$ & 99.2 & 0.661 & 10.85 & 12 & $463.9^{* *}$ \\
\hline 2. & World-II & 2001-2010 & 34 & 13,505 & $11(8-16)$ & $1-55$ & 98.2 & 1.213 & 7.47 & 33 & $1571.2^{* *}$ \\
\hline \multirow[t]{2}{*}{3.} & World-III & 2011-2019 & 82 & 142,391 & $14(11-17)$ & $2-57$ & 98.4 & 1.114 & 8.00 & 81 & $6570.4^{* *}$ \\
\hline & & \multicolumn{10}{|c|}{ Continent-wise } \\
\hline 1. & Africa & 1987-2019 & 56 & 11,217 & $11(9-13)$ & $2-41$ & 93.9 & 0.768 & 4.04 & 55 & $876.7^{* *}$ \\
\hline 2. & Asia & 1994-2019 & 31 & 12,993 & $14(9-21)$ & $1-71$ & 98.6 & 1.656 & 8.35 & 30 & $3048.0^{* *}$ \\
\hline 3. & Europe & 1996-2017 & 23 & 130,131 & $12(8-18)$ & $1-62$ & 99.4 & 1.359 & 13.12 & 22 & $3034.1^{* *}$ \\
\hline 4. & Latin America & 1980-2018 & 5 & 2147 & $15(5-36)$ & $0-95$ & 98.3 & 1.794 & 7.69 & 4 & $587.8^{* *}$ \\
\hline 5. & North America & 1982-2016 & 9 & 109,992 & $9(8-11)$ & $5-16$ & 85.3 & 0.056 & 2.61 & 8 & $64.1^{* *}$ \\
\hline 6. & Oceania & 1979-2011 & 5 & 6059 & $25(12-44)$ & $1-91$ & 98.6 & 0.929 & 8.39 & 4 & $199.1 * *$ \\
\hline
\end{tabular}


Table 4. Cont.

\begin{tabular}{|c|c|c|c|c|c|c|c|c|c|c|c|}
\hline \multirow[b]{2}{*}{ No. } & \multirow[b]{2}{*}{ Categories } & \multirow[b]{2}{*}{ Period } & \multirow[b]{2}{*}{$\begin{array}{c}\text { Number } \\
\text { of Studies }\end{array}$} & \multirow[b]{2}{*}{ Total Samples } & \multicolumn{2}{|c|}{ Pooled Estimates } & \multicolumn{5}{|c|}{ Tests of Heterogeneity } \\
\hline & & & & & $\begin{array}{c}\text { Prevalence (\%) [CI at } \\
95 \% \text { Level] }\end{array}$ & $\begin{array}{c}\text { PI (\%) at 95\% } \\
\text { Level }\end{array}$ & $\mathrm{I}^{2}$ Value (\%) & Tau Square Value & H Value & Degrees of Freedom & Cochran Q Value \\
\hline \multicolumn{12}{|c|}{ Period-wise } \\
\hline 1. & Africa-I & 1987-2010 & 15 & 3247 & $8(5-14)$ & $1-56$ & 95.4 & 1.398 & 4.65 & 14 & $315.3 * *$ \\
\hline 2. & Africa-II & 2011-2019 & 41 & 7970 & $12(9-14)$ & 3-37 & 91.9 & 0.527 & 3.52 & 40 & $493.1^{* *}$ \\
\hline 3. & Asia-I & 1994-2010 & 10 & 4655 & $11(6-19)$ & $1-62$ & 96.8 & 1.159 & 5.63 & 9 & $282.1^{* *}$ \\
\hline 4. & Asia-II & 2011-2019 & 21 & 8338 & $17(10-27)$ & $1-78$ & 98.5 & 1.780 & 8.03 & 20 & $2735.8^{* *}$ \\
\hline 5. & Europe-I & 1996-2009 & 10 & 6782 & $9(5-17)$ & $1-59$ & 98.8 & 1.213 & 9.22 & 9 & $847.9 * *$ \\
\hline 6. & Europe-II & 2011-2017 & 13 & 123,349 & $15(8-25)$ & $1-71$ & 99.2 & 1.340 & 10.93 & 12 & $1548.5^{* *}$ \\
\hline 7. & Latin America-I & 1980 & 1 & 100 & 12 & - & - & - & - & - & - \\
\hline 8. & Latin America-II & $2011-2018$ & 4 & 2047 & $16(4-44)$ & $0-100$ & 98.9 & 2.207 & 9.33 & 3 & $587.0^{* *}$ \\
\hline 9. & North America-I & 1982-2002 & 7 & 109,409 & $9(7-11)$ & $5-17$ & 89.0 & 0.067 & 3.02 & 6 & $57.6^{* *}$ \\
\hline 10. & North America-II & 2015 and 2016 & 2 & 583 & $10(8-13)$ & - & 0.0 & 0.0 & 1.00 & 1 & $0.11^{\mathrm{NS}}$ \\
\hline 11. & Oceania-I & 1982-2009 & 4 & 5955 & $23(10-46)$ & $0-98$ & 99.0 & 1.113 & 9.90 & 3 & $180.2^{* *}$ \\
\hline 12. & Oceania-II & 2011 & 1 & 104 & 34 & - & - & - & - & - & - \\
\hline \multicolumn{12}{|c|}{ Host species-wise } \\
\hline 2. & Buffalo & 2008-2017 & 7 & 1232 & $10(6-17)$ & $2-45$ & 85.8 & 0.501 & 2.66 & 6 & $49.2^{* *}$ \\
\hline \multicolumn{12}{|c|}{ Method-wise } \\
\hline 1. & $\begin{array}{c}\text { Cultural } \\
\text { Examination }\end{array}$ & 1979-2019 & 119 & 150,988 & $12(10-14)$ & $2-49$ & 98.5 & 0.939 & 8.13 & 118 & $6571.5^{* *}$ \\
\hline 2. & $\begin{array}{l}\text { Molecular } \\
\text { methods }\end{array}$ & $2007-2018$ & 10 & 121,977 & $17(8-33)$ & $1-87$ & 99.4 & 2.060 & 12.90 & 9 & $3525.2 * *$ \\
\hline 3. & Other methods & 1980 and 1994 & 2 & 347 & $3(0-21)$ & - & 86.2 & 1.874 & 2.69 & 1 & $20.7^{* *}$ \\
\hline \multicolumn{12}{|c|}{ Bacterial species-wise } \\
\hline 1. & St. acidominimus & 2010 and 2013 & 2 & 1151 & $2(1-3)$ & - & 0.0 & 0.0 & 1.00 & 1 & $4.47^{*}$ \\
\hline 2. & St. agalactiae & 1979-2018 & 83 & 138,904 & $9(7-12)$ & $1-57$ & 99.0 & 1.662 & 10.07 & 82 & $6296.6^{* *}$ \\
\hline 3. & St. anginosus & 1994 and 2010 & 2 & 281 & $1(0-3)$ & - & 0.0 & 0.0 & 1.00 & 1 & $1.73^{\mathrm{NS}}$ \\
\hline 4. & St. bovis & 2010 and 2011 & 4 & 321 & $3(1-5)$ & $1-11$ & 0.0 & 0.0 & 1.00 & 3 & $1.66^{\mathrm{NS}}$ \\
\hline 5. & St. constellatus & 2010 & 1 & 34 & 3 & - & - & - & - & - & - \\
\hline 6. & St. dysgalactiae & 1980-2018 & 55 & 141,844 & $6(5-8)$ & $1-36$ & 98.5 & 1.152 & 8.28 & 54 & $3131.1^{* *}$ \\
\hline
\end{tabular}


Table 4. Cont.

\begin{tabular}{|c|c|c|c|c|c|c|c|c|c|c|c|}
\hline \multirow[b]{2}{*}{ No. } & \multirow[b]{2}{*}{ Categories } & \multirow[b]{2}{*}{ Period } & \multirow{2}{*}{$\begin{array}{c}\text { Number } \\
\text { of Studies }\end{array}$} & \multirow[b]{2}{*}{ Total Samples } & \multicolumn{2}{|c|}{ Pooled Estimates } & \multicolumn{5}{|c|}{ Tests of Heterogeneity } \\
\hline & & & & & $\begin{array}{c}\text { Prevalence (\%) [CI at } \\
\text { 95\% Level] }\end{array}$ & $\begin{array}{c}\text { PI (\%) at } 95 \% \\
\text { Level }\end{array}$ & $\mathrm{I}^{2}$ Value (\%) & Tau Square Value & H Value & Degrees of Freedom & Cochran Q Value \\
\hline 7. & St. equinus & 2001-2011 & 4 & 1571 & $2(1-5)$ & $0-40$ & 75.4 & 0.436 & 2.02 & 3 & $23.8^{* *}$ \\
\hline 8. & St. equisimilis & 2017 & 1 & 65 & 3 & - & - & - & - & - & - \\
\hline 9. & St. faecalis & 2002-2017 & 4 & 385 & $4(2-8)$ & $0-46$ & 50.2 & 0.339 & 1.42 & 3 & $8.15^{*}$ \\
\hline 10. & St. intermedius & 2017 & 2 & 319 & $6(4-10)$ & - & 0.0 & 0.0 & 1.00 & 1 & $0.27^{\mathrm{NS}}$ \\
\hline 11. & St. mitis & 2011 and 2018 & 2 & 104 & $2(0-7)$ & - & 0.0 & 0.0 & 1.00 & 1 & $1.45^{\mathrm{NS}}$ \\
\hline 12. & $\begin{array}{c}\text { St. } \\
\text { plurianimalium } \\
\end{array}$ & 2017 & 1 & 65 & 1.5 & - & - & - & - & - & - \\
\hline 13. & St. pneumonia & 2009 & 1 & 71 & 1.4 & - & - & - & - & - & - \\
\hline 14. & St. pyogenes & 2014 & 1 & 47 & 10.6 & - & - & - & - & - & - \\
\hline 15. & St. salivaris & 2010 & 1 & 34 & 2 & - & - & - & - & - & - \\
\hline 16. & St. sanguinis & 2011-2018 & 2 & 104 & $8(0-63)$ & - & 86.6 & 4.151 & 2.73 & 1 & $20.1 * *$ \\
\hline 17. & St. uberis & 1980-2018 & 52 & 139,050 & $9(7-12)$ & $1-53$ & 99.0 & 1.429 & 9.96 & 51 & $4000.7^{* *}$ \\
\hline 18. & St. zooеpidemicus & 2010 & 1 & 130 & 3.9 & - & - & - & - & - & - \\
\hline 19. & St. species & 1982-2019 & 48 & 120,504 & $10(8-12)$ & $2-37$ & 97.5 & 0.687 & 6.30 & 47 & 959.9 ** \\
\hline 2. & Clinical mastitis & 1982-2019 & 26 & 16,848 & $13(8-20)$ & $1-72$ & 99.2 & 1.811 & 11.13 & 25 & $2556.0^{* *}$ \\
\hline 3. & Mastitis & 1982-2018 & 63 & 242,838 & $11(9-15)$ & $1-53$ & 99.5 & 1.138 & 14.49 & 62 & $5973.1^{* *}$ \\
\hline
\end{tabular}


Table 5. Escherichia coli prevalence estimates in the world based on various subgroup meta-analyses.

\begin{tabular}{|c|c|c|c|c|c|c|c|c|c|c|c|}
\hline \multirow[b]{2}{*}{ No. } & \multirow[b]{2}{*}{ Categories } & \multirow[b]{2}{*}{ Period } & \multirow[b]{2}{*}{$\begin{array}{l}\text { Number of } \\
\text { Studies }\end{array}$} & \multirow[b]{2}{*}{ Total Samples } & \multicolumn{2}{|c|}{ Pooled Estimates } & \multicolumn{5}{|c|}{ Tests of Heterogeneity } \\
\hline & & & & & $\begin{array}{l}\text { Prevalence (\%) } \\
\text { [CI at 95\% Level] }\end{array}$ & $\begin{array}{c}\text { PI (\%) at } 95 \% \\
\text { Level }\end{array}$ & $\mathrm{I}^{2}$ Value (\%) & $\begin{array}{l}\text { Tau Square } \\
\text { Value }\end{array}$ & H Value & $\begin{array}{l}\text { Degrees of } \\
\text { Freedom }\end{array}$ & $\begin{array}{l}\text { Cochran } \\
\text { Q Value }\end{array}$ \\
\hline 1. & World & 1996-2019 & 92 & 257,473 & $11(9-13)$ & $1-50$ & 98.9 & 1.154 & 9.68 & 91 & $17,511.1^{* *}$ \\
\hline \multicolumn{12}{|c|}{ Year-wise } \\
\hline 1. & World-I & 1996-2000 & 5 & 113,108 & $5(1-20)$ & $0-95$ & 99.8 & 2.685 & 24.61 & 4 & $10,139.0 * *$ \\
\hline 2. & World-II & $2001-2010$ & 23 & 8918 & $11(7-16)$ & $1-52$ & 97.7 & 1.088 & 6.59 & 22 & $540.3^{* *}$ \\
\hline 3. & World-III & 2011-2019 & 64 & 135,447 & $11(40-47)$ & $12-80$ & 98.2 & 0.962 & 7.39 & 63 & $3439.4^{* *}$ \\
\hline \multicolumn{12}{|c|}{ Continent-wise } \\
\hline 1. & Africa & 2006-2018 & 45 & 8142 & $10(8-14)$ & $1-50$ & 95.6 & 1.093 & 4.77 & 44 & $792.0^{* *}$ \\
\hline 2. & Asia & 2002-2019 & 21 & 11,561 & $12(9-17)$ & $3-42$ & 97.0 & 0.579 & 5.80 & 20 & $394.7 * *$ \\
\hline 3. & Europe & 1996-2017 & 16 & 129,580 & $10(6-15)$ & $1-53$ & 99.6 & 1.128 & 15.67 & 15 & $5117.3^{* *}$ \\
\hline 4. & Latin America & 2013 & 1 & 1117 & 2 & - & - & - & - & - & - \\
\hline 5. & North America & 1997-2016 & 8 & 106,969 & $11(4-27)$ & $0-87$ & 99.1 & 2.396 & 10.74 & 7 & $1399.0^{* *}$ \\
\hline 6. & Oceania & 2011 & 1 & 104 & 28 & - & - & - & - & - & - \\
\hline \multicolumn{12}{|c|}{ Period-wise } \\
\hline 1. & Africa-I & 2006-2010 & 6 & 636 & $5(2-12)$ & $0-49$ & 83.1 & 0.860 & 2.43 & 5 & $30.1 * *$ \\
\hline 2. & Africa-II & 2011-2018 & 39 & 7506 & $11(8-15)$ & $2-51$ & 95.8 & 1.038 & 4.88 & 38 & $714.9^{* *}$ \\
\hline 3. & Asia-I & $2002-2010$ & 6 & 4309 & $9(6-12)$ & $2-27$ & 87.6 & 0.199 & 2.85 & 5 & $28.6^{* *}$ \\
\hline 4. & Asia-II & 2011-2019 & 15 & 7252 & $15(10-21)$ & $3-48$ & 96.8 & 0.578 & 5.63 & 15 & $249.9^{* *}$ \\
\hline 5. & Europe-I & 1996-2009 & 11 & 11,089 & $12(6-20)$ & $1-61$ & 99.1 & 1.103 & 10.61 & 10 & $679.6^{* *}$ \\
\hline 6. & Europe-II & 2011-2017 & 5 & 118,491 & $6(3-14)$ & $0-62$ & 97.0 & 0.810 & 5.73 & 4 & $75.2^{* *}$ \\
\hline 8. & Latin America-II & 2013 & 1 & 1117 & 2 & - & - & - & - & - & - \\
\hline 9. & North America-I & 1997-2010 & 5 & 105,992 & $12(3-44)$ & $0-99$ & 99.5 & 3.742 & 14.16 & 4 & $1062.1^{* *}$ \\
\hline 10. & North America-II & 2013-2016 & 3 & 977 & $9(8-11)$ & $2-29$ & 0.0 & 0.0 & 1.00 & 2 & 0.09 NS \\
\hline 12. & Oceania-II & 2011 & 1 & 104 & 28 & - & - & - & - & - & - \\
\hline \multicolumn{12}{|c|}{ Host species-wise } \\
\hline 1. & Cattle & 1996-2019 & 89 & 256,295 & $10(8-13)$ & $1-51$ & 99.0 & 1.187 & 9.82 & 88 & $16,809.4^{* *}$ \\
\hline 2. & Buffalo & 2011-2018 & 6 & 1178 & $25(9-52)$ & $0-96$ & 97.9 & 2.070 & 6.84 & 5 & $167.2^{* *}$ \\
\hline
\end{tabular}


Table 5. Cont.

\begin{tabular}{|c|c|c|c|c|c|c|c|c|c|c|c|}
\hline \multirow[b]{2}{*}{ No. } & \multirow[b]{2}{*}{ Categories } & \multirow[b]{2}{*}{ Period } & \multirow[b]{2}{*}{$\begin{array}{l}\text { Number of } \\
\text { Studies }\end{array}$} & \multirow[b]{2}{*}{ Total Samples } & \multicolumn{2}{|c|}{ Pooled Estimates } & \multicolumn{5}{|c|}{ Tests of Heterogeneity } \\
\hline & & & & & $\begin{array}{c}\text { Prevalence (\%) } \\
\text { [CI at 95\% Level] }\end{array}$ & $\begin{array}{l}\text { PI (\%) at } 95 \% \\
\text { Level }\end{array}$ & $\mathrm{I}^{2}$ Value (\%) & $\begin{array}{c}\text { Tau Square } \\
\text { Value }\end{array}$ & H Value & $\begin{array}{c}\text { Degrees of } \\
\text { Freedom }\end{array}$ & $\begin{array}{l}\text { Cochran } \\
\text { Q Value }\end{array}$ \\
\hline \multicolumn{12}{|c|}{ Method-wise } \\
\hline 1. & $\begin{array}{c}\text { Cultural } \\
\text { Examination }\end{array}$ & 1996-2019 & 87 & 131,774 & $10(8-12)$ & $1-47$ & 97.5 & 1.056 & 6.29 & 86 & $10,463.3^{* *}$ \\
\hline 2. & $\begin{array}{c}\text { Molecular } \\
\text { methods }\end{array}$ & 1998-2018 & 8 & 125,838 & $23(11-42)$ & $1-89$ & 99.8 & 1.662 & 25.41 & 7 & $5387.8^{* *}$ \\
\hline \multicolumn{12}{|c|}{ Type of mastitis } \\
\hline 2. & Clinical mastitis & 1996-2019 & 16 & 15,337 & $19(14-25)$ & $5-52$ & 98.4 & 0.494 & 7.79 & 15 & $687.8^{* *}$ \\
\hline 3. & Mastitis & $1997-2018$ & 47 & 236,011 & $9(6-12)$ & $1-50$ & 98.9 & 1.312 & 9.59 & 46 & $8384.4^{* *}$ \\
\hline
\end{tabular}




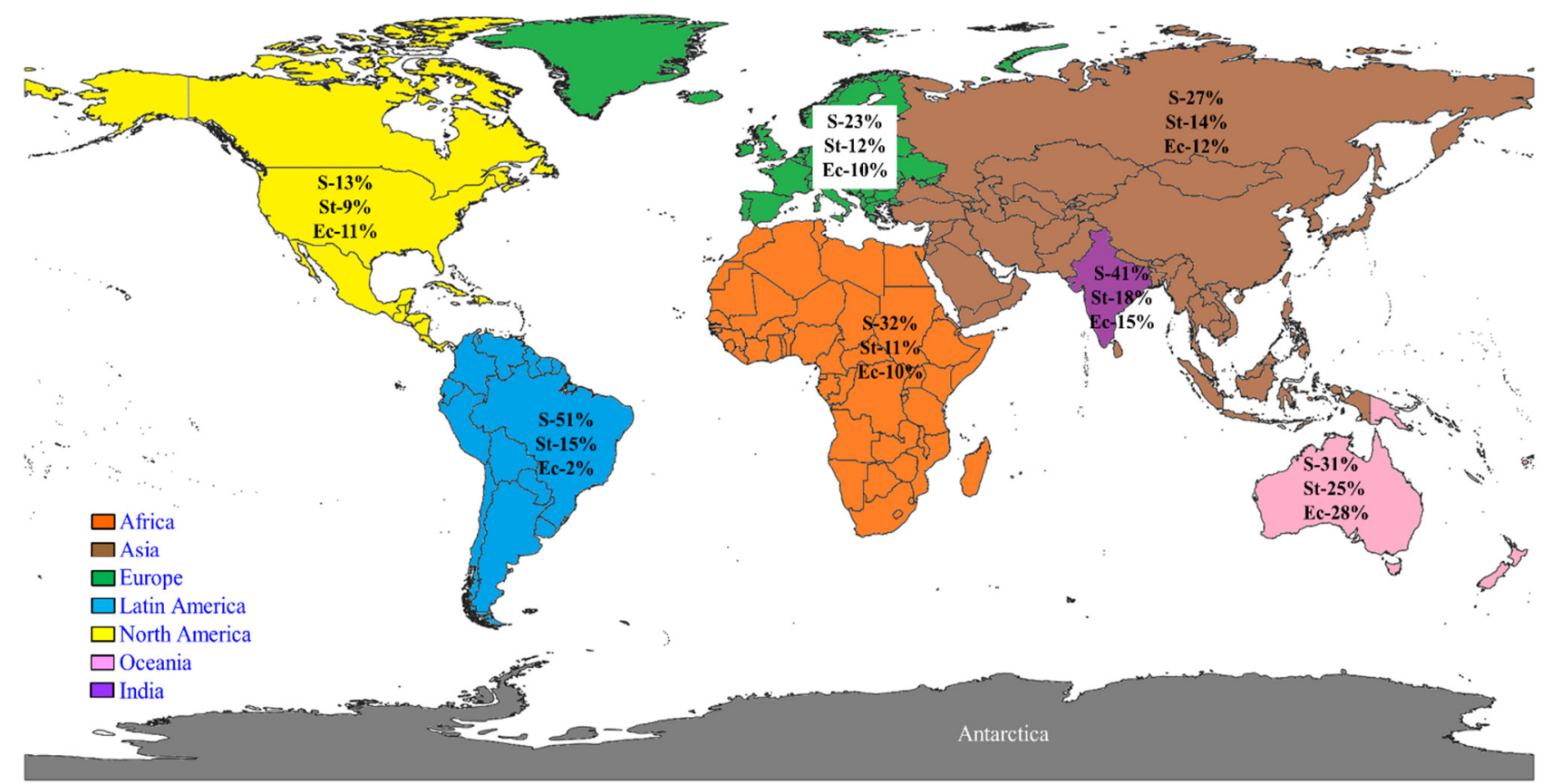

Figure 2. World map showing the continent-wise prevalence of Staphylococcus species (S), Streptococcus species (St), and Escherichia coli (Ec).

\subsection{The S, St, and Ec Prevalence in Various Countries}

The details of S, St, and Ec prevalence estimates obtained for various countries of the world analyzed by meta-analysis are presented in Figures $3-5$, respectively. The $S$ prevalence was highest in Trinidad and Tobago (98\%), followed by Sri Lanka (90\%); in other countries, a low prevalence was observed in Vietnam (5\%). A higher St prevalence was observed in Brazil (67\%), followed by the United Kingdom (49\%); there was a low prevalence in other countries like Jordan (1\%), Tanzania (2\%), Zimbabwe (3\%). The Ec prevalence was high in Australia (28\%) and Iraq (24\%), and it was low in Croatia and Rwanda (1\%), as shown in Figure 5. The countrywide $S$ prevalence studies showed a highly significant $(p<0.01)$ difference based on Cochran Q statistics for the various countries except for Canada, Iraq, Kenya, and Netherlands with a significant $(p<0.05)$ difference, and there was no significant difference for Algeria, Indonesia, and Italy-specifying no heterogeneity in studies. A highly significant $(p<0.01)$ difference for Cochran $Q$ values for St prevalence studies was observed except for Germany; Nigeria revealed a significant $(p<0.05)$ difference, and Algeria, Czech Republic, Italy, Jordan, and Kenya showed no significant differences. 


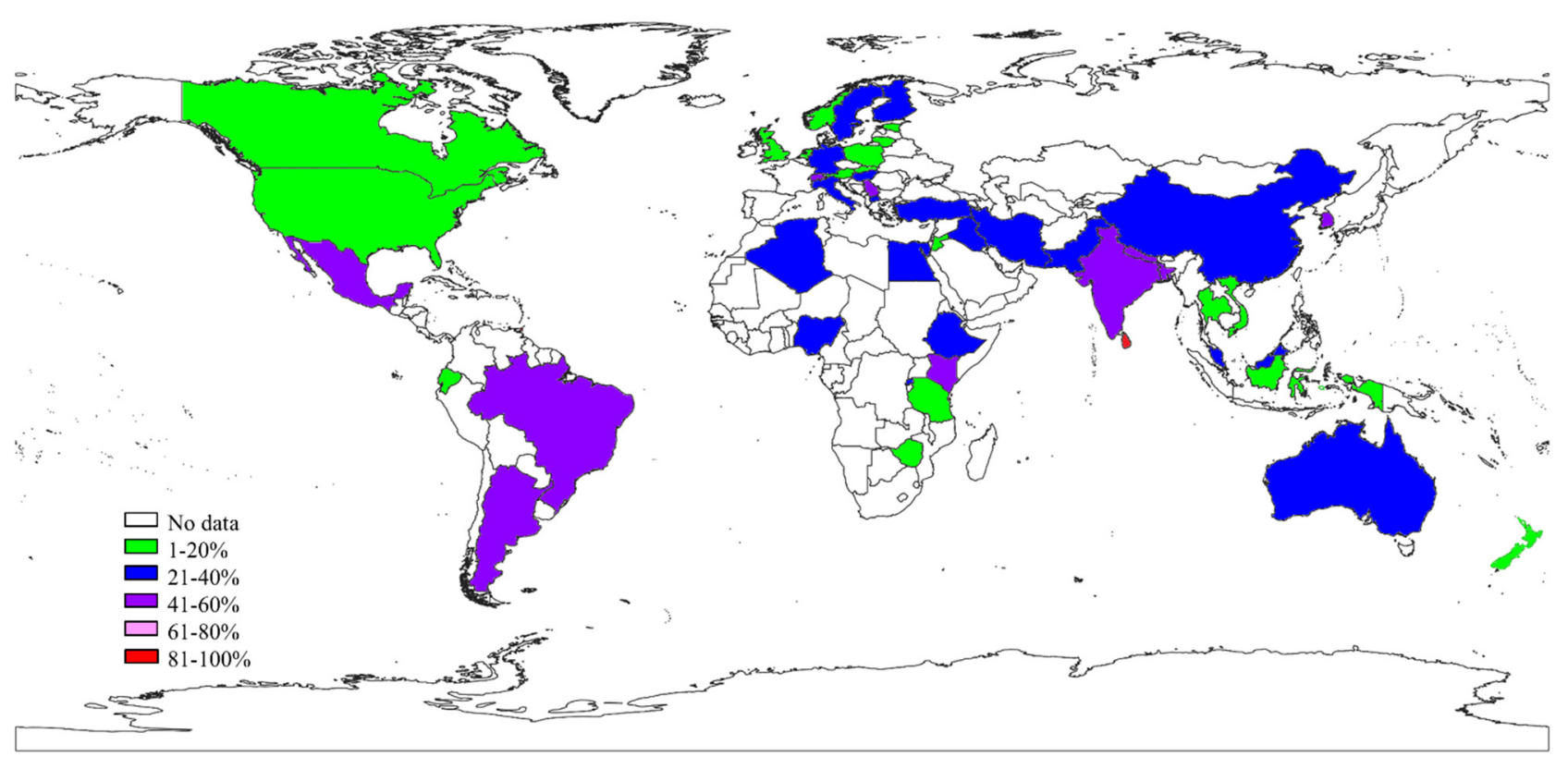

Figure 3. World map showing the prevalence estimates of Staphylococcus species in different countries.

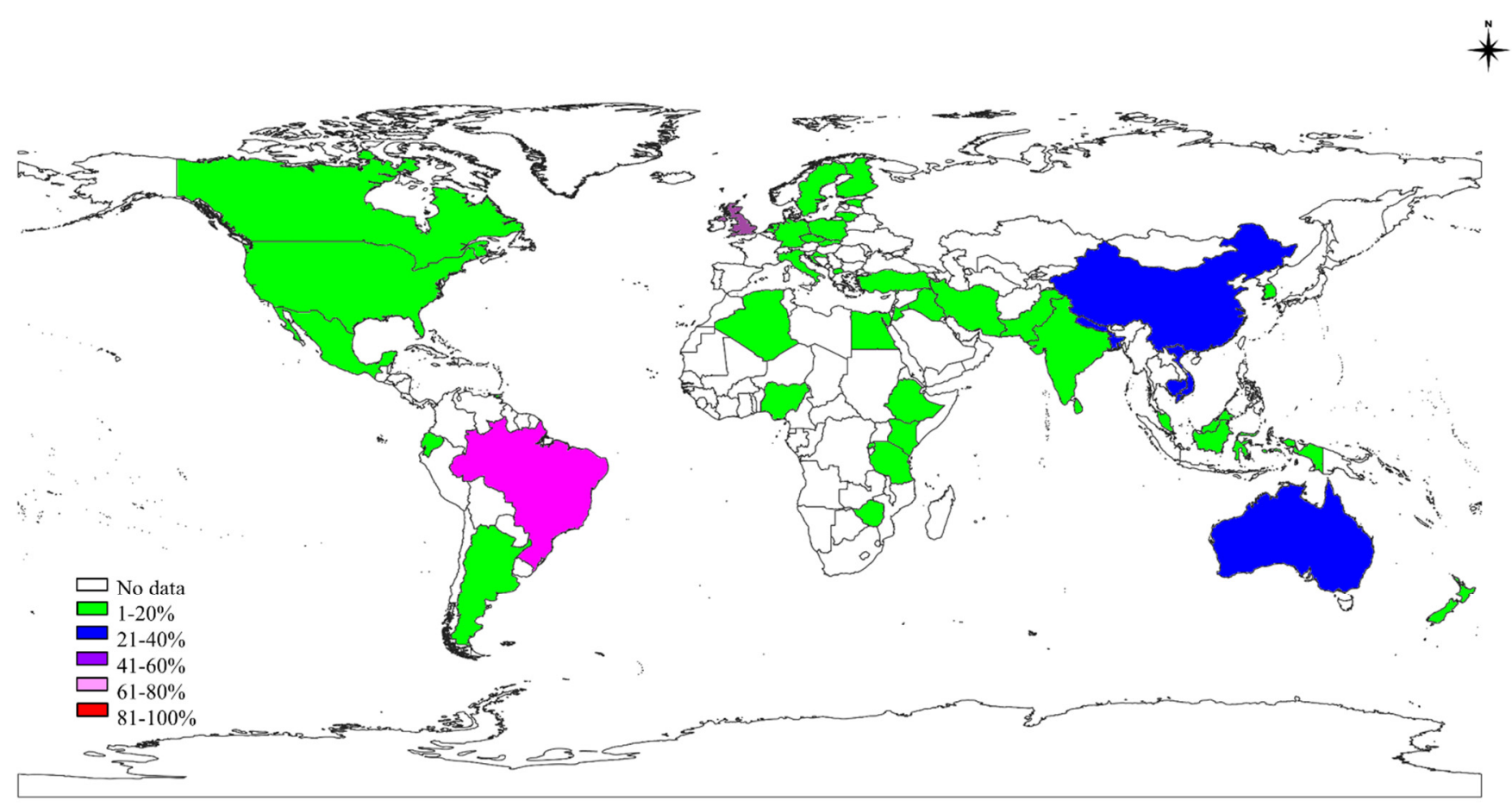

Figure 4. World map showing the prevalence estimates of Streptococcus species in different countries. 


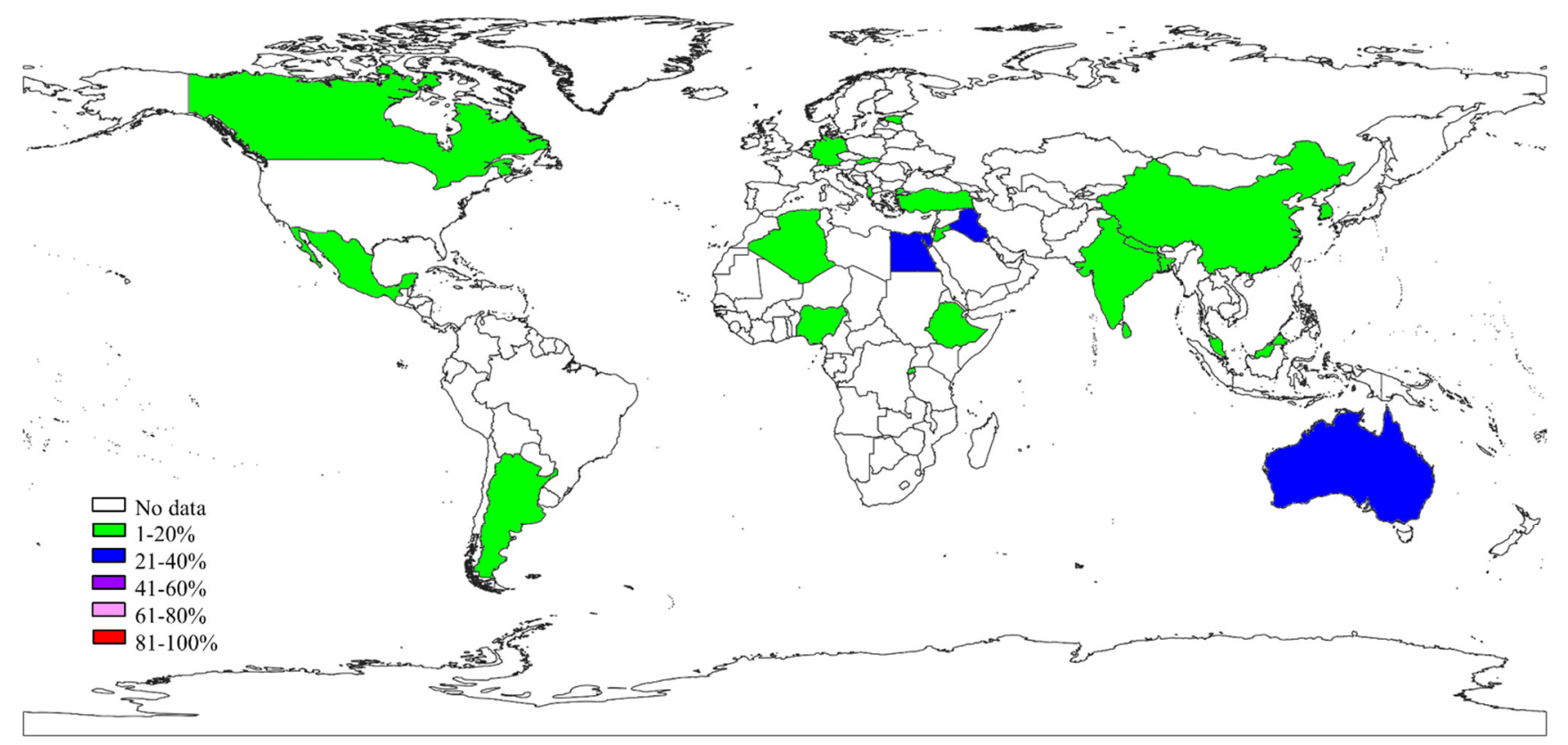

Figure 5. World map showing the prevalence estimates of Escherichia coli in different countries.

The particulars of S, St, and Ec prevalence estimates obtained for India based on period, zone, state, species, method, bacterial species, and type of mastitis are shown in Supplementary File S2. The pooled prevalence estimates of S, St, and Ec in India were $41 \%$, $18 \%$, and $15 \%$, respectively, obtained from $14,011,12,314$, and 12,288 milk samples. The details of zone-wise and state-wise prevalence estimates of S, St, and Ec in India are shown in Figure 6. Higher S, St, and Ec prevalences in the south zone (43\%), north zone (23\%), and east and south zones (16\%), respectively, were observed. The state-wise breakdown revealed the highest S, St, and Ec prevalences in Mizoram and Uttarakhand (67\%), Odisha $(32 \%)$, and Kerala (42\%), respectively. Low prevalences of S, St, and Ec were observed in Jharkhand $(21 \%)$, Sikkim $(3 \%)$, and Uttarakhand $(3 \%)$, respectively. The publication bias p-values estimated by Begg's test were 0.609, 0.923, and 0.869 for S, St, and Ec, respectively, which implied no publication bias among the studies from India included for obtaining pooled prevalence estimates. 


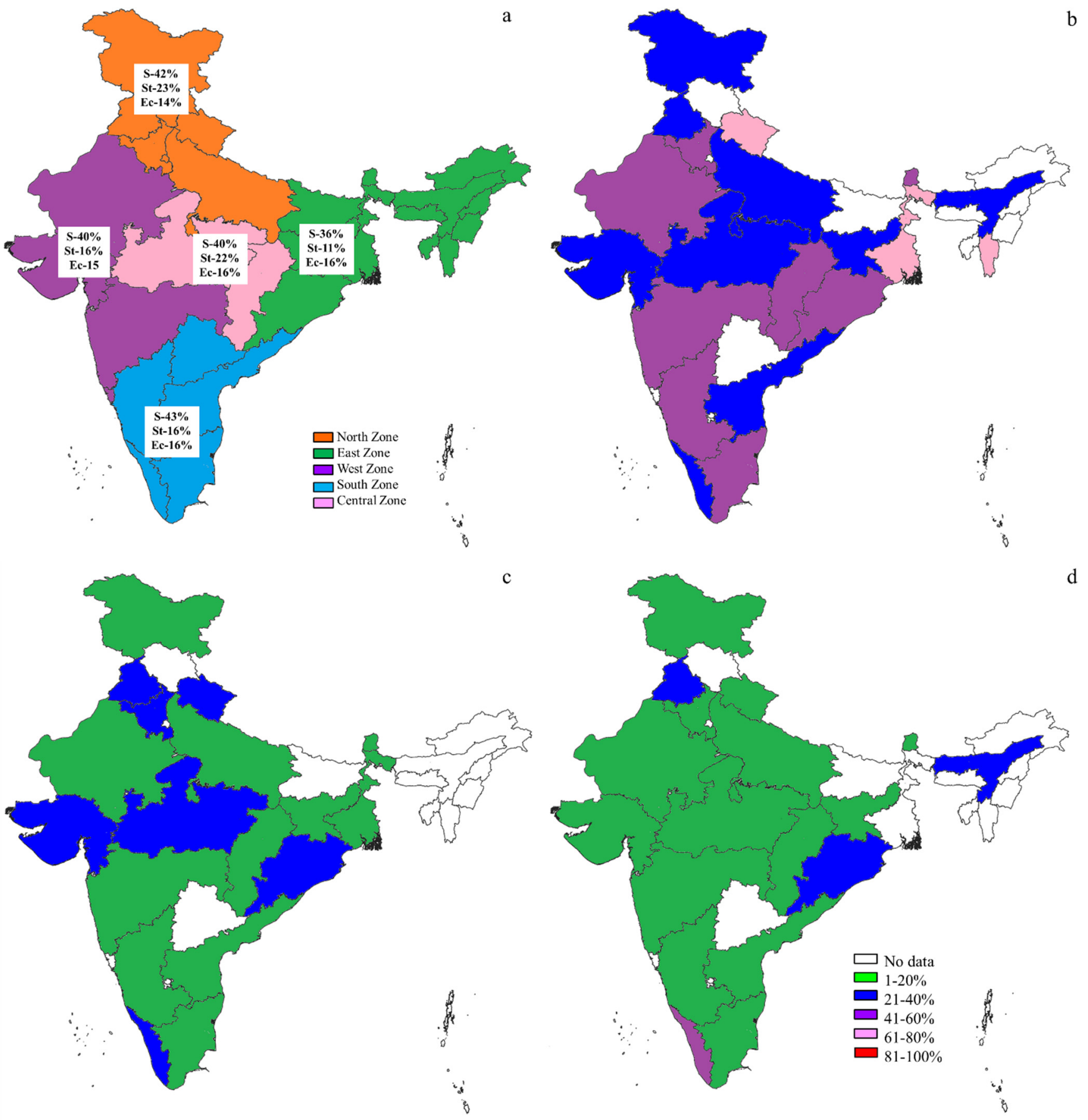

Figure 6. Zone-wise (a) and state-wise prevalence of Staphylococcus species (b), Streptococcus species (c), and Escherichia coli (d).

\section{Discussion}

Bovine mastitis is considered to be a hundred-year-old production disease [1] and still challenging to prevent, even with advances in technological interventions for diagnosis and treatment, mainly due to the multi-etiological nature of the disease. The presence of bacterial species in raw milk affects not only the udder health of dairy cattle and buffalo but also human health by the possible transmission of antimicrobial resistance. The metaanalysis has been gaining importance in recent years in determining livestock disease prevalence estimates, as described earlier [5]. The $\mathrm{S}$ species, St species, and Ec prevalences were found to be $28 \%, 12 \%$, and $11 \%$, respectively, in the world based on the current meta-analysis. However, a study from Iran reported a higher prevalence of $S$ species in 
mastitis-71.5\% in milk [15]—in comparison to the present study. The Staphylococcus aureus is considered to be the main mastitis pathogen among the three pathogens in the world based on the present study, which was in agreement with previous reports from Norway, Australia, the United States of America, Italy, Tanzania, and Finland, as well as a 100-year review on bovine mastitis [1,16-21]. The prevalence of coagulase-negative Staphylococcus (CNS) species obtained in the present study agreed with a previous study that indicated the prevalences of subclinical and clinical mastitis at 6-72\% and 6-30\%, respectively [22].

The importance of CNS species in mastitis cases in Iran was previously described [15]. The pathogenic microorganisms enter through the teat canal and result in physical, chemical, and pathological changes in the udder and milk $[13,14]$. The foremost factors responsible for the occurrence of mastitis may be determined by the exposure to microorganisms, the immune mechanism of dairy cows, managemental factors, and environmental factors, as described in [14]. The environment plays an important role in the spread of mastitis pathogens in dairy cattle, e.g., the horn flies reported in [18]. In a previous study, S. aureus was isolated from heifer body sites, environments, human beings, and horn flies in a farm, and similar or identical genotypes were isolated from the cow milk samples [18], suggesting that $S$ species infection predominantly comes from the environment (except for S. aureus) and mainly causes subclinical mastitis. Furthermore, there were more studies in more countries on S prevalence than St and Ec, which confirms the significance of $S$ species in various countries of the world.

The number of countries showing a higher $S$ prevalence estimate was 41 whereas, the higher prevalence of St in 6 and Ec in 2 countries were observed. This finding was crucial for showing $S$ species as important mastitis pathogen sources in many countries of the world. A higher St prevalence was noticed in Brazil, China, New Zealand, Thailand, the United Kingdom, and Vietnam, and a higher Ec prevalence was noticed in Canada and Sri Lanka-suggesting the significance of St and Ec as the principal mastitis pathogens in these countries. A year-wise evaluation revealed that the $S$ and St species increased during 2011-2019 in comparison to past years, which may have been due to advances in the diagnosis of intramammary infections in bovine populations [21,23] and the use of molecular methods for bacterial identification. A continent-wise analysis showed a higher prevalence of S in Latin America and higher prevalences of St and Ec in Oceania, which was corroborated with the earlier studies [24,25]. However, more studies were reported from Africa, signifying the importance of the mastitis problem in the countries of such. This might because of the low economic status, poor husbandry practices, and dairy management practices of African countries. The countries in Latin America predominately have grass-dependent production systems, and the risk of exposure to environmental pathogens is greater than in other countries where cows are housed in sheds, as described in [24]. The worldwide St species prevalence was found to be $12 \%$, and the most common bacterial species among them were St. agalactiae and St. uberis (9\% each), which agreed with a previous study that indicated $S t$. uberis as a common environmental bacteria causing clinical mastitis and infecting dairy heifers from a pasture grazing rearing system in New Zealand [25]. Among cattle and buffalo, higher S and Ec prevalences were observed in buffalo, and a higher St prevalence was observed in cattle. The higher prevalence of $S$ species in buffalo was reported earlier in a study from Pakistan [26], which agreed with the present study. Furthermore, regarding the diagnostic methods employed for the identification of mastitis pathogens, the molecular methods revealed higher prevalence estimates for all three pathogens. This signified the higher sensitivity of molecular methods in the identification of bacterial pathogens isolated from milk in dairy cattle and buffalo, and these methods may be used in future studies. However, the majority of the studies employed cultural examination and biochemical tests for the confirmation of bacterial species isolated from milk samples in various countries. This might have been because isolation and identification via cultural examination and biochemical tests are easier and more cost-effective for bacterial species identification than molecular methods, which are usually costly. Among the S and St species, S. aureus, St. agalactiae, and St. uberis revealed 
higher prevalences, suggesting the importance of these species in mastitis, which is in agreement with the previous studies $[18,24,25]$. In a study conducted in Nigeria with mastitis cows, the Streptococci species was considered to be an environmental pathogen accountable for a high proportion of mastitis cases, mainly with St. uberis [27]. Furthermore, there was a considerable prevalence of St. dysgalactiae in mastitis cases in the dairy herds of China [28], as corroborated by the present study. Higher S, St, and Ec prevalences were observed in subclinical mastitis and clinical mastitis. The $\mathrm{S}$ species are more crucial in subclinical mastitis than in clinical mastitis, mostly contributing as contagious (especially $S$. aureus and environmental pathogens) and leading to production loss without any clinical signs and was in agreement with previous reports $[19,22]$. However, Ec has a greater chance of causing severe, acute mastitis before forming clinical mastitis cases compared to other bacterial pathogens. Coliform organisms were reported to cause severe clinical mastitis in cattle and buffalo [13], in agreement with the present study. Among the three major pathogens, the St species was present in both the forms of mastitis, i.e., subclinical and clinical mastitis, in dairy cattle and buffalo of the world. The mastitis caused by these microorganisms can be prevented by following proper husbandry practices such as using proper milking systems, engaging in hand disinfection before milking, milking affected cows at the end, conducting frequent testing for mastitis, appropriately using dry cow therapy, and removing chronically infected dairy cows from the farm as necessary [29]. The geographical location of the farm, used bedding materials, and season may be considered while planning mastitis control and prevention strategies in dairy farms, as mentioned earlier [30]. Furthermore, clean and safe milk production is important for the health of humans as a whole because milk forms an essential part of food in almost all the countries of the world.

In India, the prevalences of S, St, and Ec were reported to be $41 \%, 18 \%$, and $15 \%$, respectively, and the major mastitis pathogen was the $S$ species (similar to the rest of the world). A previous study on major mastitis pathogen prevalences in dairy cattle in India reported $45 \%, 13 \%$, and $14 \%$ for S, St, and Ec, respectively, based on a meta-analysis of studies from the limited period of 2005-2016 [6]; this was corroborated by the present study, which included studies reported during 1995-2019. The findings from the present study were in agreement with the previous reports that indicated the $S$ species as a major mastitis pathogen of subclinical mastitis in cows [31-33]. Based on a zone-wise analysis, higher S, St, and Ec prevalences were observed in the south, north, and east and south zones, respectively. As reported here, the highest prevalence of $S$ was in Uttarakhand and Mizoram (67\%), highest prevalence of St was in Odisha (32\%), and Ec prevalence was highest in Kerala (42\%) based on state-wise analysis. The S, St, and Ec prevalences were lowest in Jharkhand, Sikkim, and Uttarakhand, respectively. It was shown that there were variations in the occurrence of mastitis pathogens in different states, and it is necessary to take up preventive and control measures accordingly. The variations in the mastitis pathogen prevalence might be due to differences in the management, feeding, and husbandry practices among the states in India. S and Ec occur due to unclean milking practices, contaminated environments, dairy farmworkers and the pathogens enter through the teat canal, causing infection in the udder as reported earlier [34]). Cattle showed a higher prevalence of St and Ec than buffalo, but the S prevalence was higher in buffalo. Furthermore, a comprehensive examination of milk could offer important evidence concerning the nature of mastitis in dairy cattle and buffalo [35]. Bacterial species-wise prevalence estimates in this study were higher for S. aureus (38\%) and St. dysgalactiae (15\%), which were in agreement with a previous report [36]. Moreover, S. aureus in milk leads to food poisoning in human beings and is considered a public health concern. Further, an S. aureus presence in milk and milk products indicates poor quality [36]. St. dysgalactiae was considered a contagious mastitis pathogen in developed countries, namely the USA and UK, as described earlier [37,38]. In India, Ec was observed to be second in prevalence following $S$ species, which is in contrast to the many reports [39-41]. According to the type of mastitis, $\mathrm{S}$ was prevalent in subclinical mastitis and St and Ec were present in both 
subclinical and clinical mastitis; similar observations were previously reported [33,38]. This also confirms that $S$ species cause a subclinical and chronic form of mastitis and that Ec leads to a clinical and acute form of mastitis in dairy cattle and buffalo.

As this report attempted to estimate the worldwide prevalence of mastitis pathogens for the first time and to find the major worldwide mastitis pathogens, a few limitations must be disclosed. The prevalence estimates did not include the association of mastitis occurrence with various risk factors. The risk factors included the cattle and buffalo breeds, genetic character of the breed, lactation stage, number of lactations, milk yield or production, followed farm management practices, climatic factors, and the geographical location of the reported studies, all of which may have resulted in variation among the mastitis pathogen prevalence $[6,42]$. The studies included for meta-analysis were from 49 countries that have reported major mastitis pathogen prevalences and are available in online databases and offline literature, and some countries may have had small numbers of studies but nonetheless gave estimates for the various mastitis pathogens in the world. Further studies on mastitis pathogens are required from other countries to obtain more accurate prevalence estimates. Some of the countries only had a few studies included for meta-analysis and thus may not have given a true picture of the country. The studies were comprehensively collected from different online databases and offline resources in the present study. However, the comprehensiveness of all the studies reported should be investigated in a future meta-analysis because is very important to more precisely determine the prevalence estimates. Many other bacterial species might cause subclinical and clinical mastitis, but in the present study, only three important bacterial pathogens were considered for the world. The studies collated in this report will form a resource on major mastitis pathogen prevalence studies, enabling simple access for the researchers on mastitis in upcoming years.

\section{Materials and Methods}

\subsection{Literature Search}

The literature search was systematically carried out by using keywords for the identification of prevalence studies on Staphylococcus (S) species, Streptococcus (St) species, and Escherichia coli (Ec) in milk. The preferred reporting items for systematic reviews and metaanalyses (PRISMA) guidelines were followed in the selection of major mastitis pathogen prevalence studies from the world [43]. A flow chart detailing the number of S, St, and Ec prevalence studies retrieved, reviewed in full, and collated for the meta-analysis for the world and India is given in Figure 7. The search terms used were "prevalence of mastitis pathogens, prevalence of Staphylococcus species, prevalence of Streptococcus species, and prevalence of Escherichia coli," not including the Boolean operators. The online databases searched were Consortium of e-Resources in Agriculture (CeRA) under the Indian Council of Agricultural Research, Elsevier, Google Scholar, Indian journals.com, PubMed, Springer, and Web of science. Around 273 and 152 articles from the world and India, respectively, were identified based on various database searches. The selection of the studies was based on the characteristics of journal articles, including author names, publication year, country, state, number of positive samples, number of samples tested, engaged diagnostic methods, host species (either cattle or buffalo), identified bacterial species, and milk samples from subclinical or clinical mastitis or mastitis in general. Finally, the selected journal articles were reviewed in detail, and the cited references were used for back-searching for pertinent studies. The reported studies included for data extraction were limited to the period from January 1979 to December 2019, and the studies were only written in the English language. 


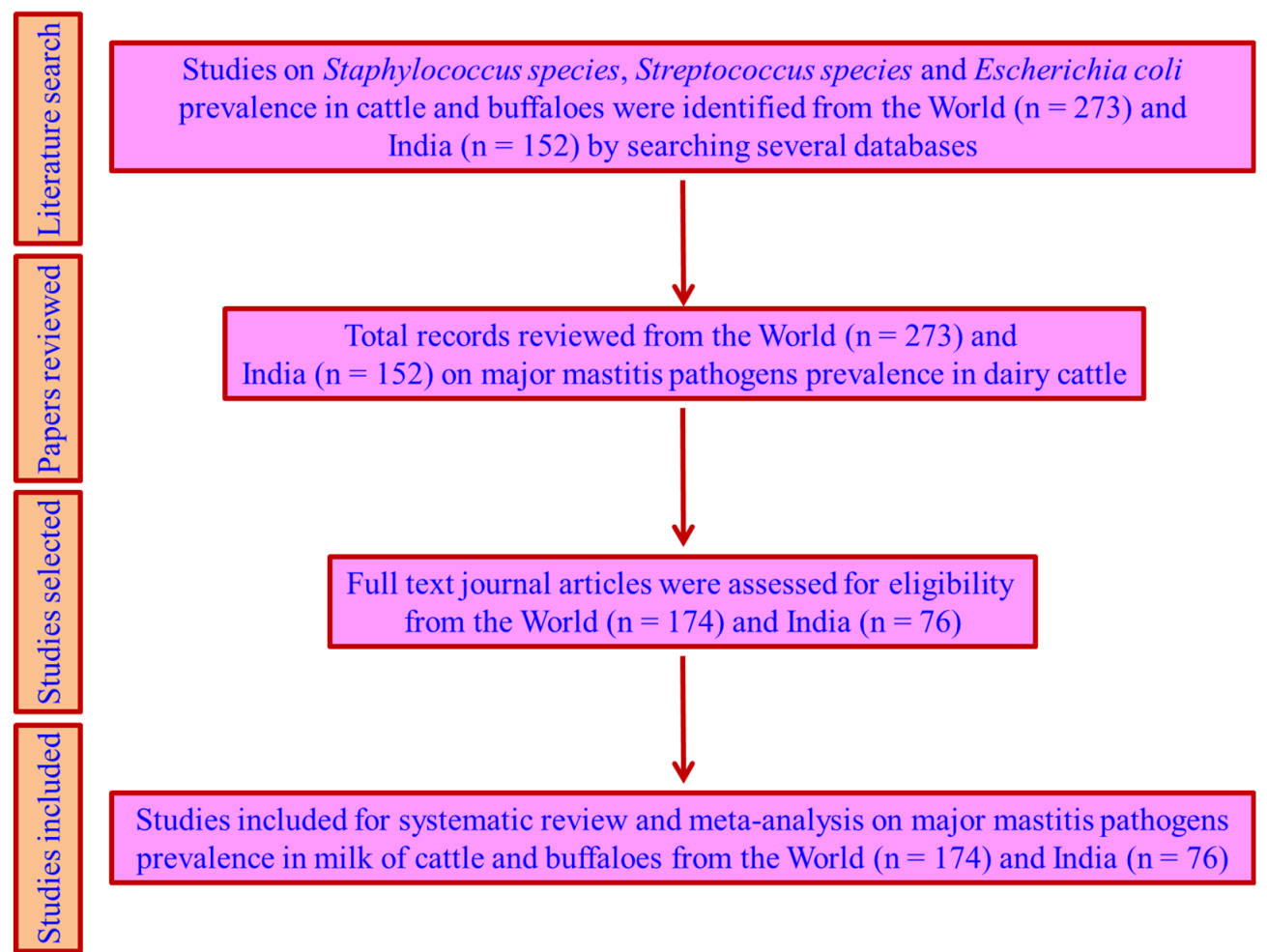

Figure 7. Flow chart showing review and selection of studies for meta-analysis.

\subsection{Extraction of Data}

The prevalence reports on major mastitis pathogens were thoroughly reviewed and based on fixed inclusion and exclusion criteria encompassed for a meta-analysis. The inclusion criteria comprised both longitudinal and cross-sectional studies reported in the journal articles, mainly with details mentioned below in the characteristics of the studies from the countries of the world, and exclusion criteria were case reports and review articles. The study details were extracted from the characteristics reported in each study into a predesigned format in Microsoft Excel sheets. These characteristics were author names; year of publication; species of animals tested (cattle, buffalo, or both); number of samples positive for S, St, and Ec; the total number of samples tested; prevalences of S, St, and Ec; the applied diagnostic methodologies; and the types of mastitis cases. The particulars of employed diagnostic methods were bacterial cultural examination (e.g., isolation, cultural characters, and biochemical and phenotypic tests), molecular methods (e.g., established on nucleic acid methods), and other methods. Among the employed diagnostic methods and identified bacterial species, the highest prevalence values obtained by a method or a bacterial species in the $\mathrm{S}$ and St groups were included for meta-analysis wherever applicable. The data sorting was done based on a three-step methodology, as stated earlier [7].

\subsection{Quality Assessment of Studies}

The quality assessment of the prevalence studies selected for a meta-analysis was done by a fixed rating scale devised in a previous study [44] with some modifications as mentioned below. The rating scale involved the following parameters: sample representation, size of the sample, methods employed for pathogen identification, prevalence values, and assessment of the outcome, with each having a maximum score of 2, 2, 2, 2, and 2, respectively. The maximum score obtained for the quality assessment of the study was 10 , and the minimum required score was 5 for the inclusion of the studies in the meta-analysis. 


\subsection{Statistical Analysis}

The meta-analysis was performed in R Open source scripting software version 3.2.5 (Comprehensive R Archive Network, Vienna, Austria) by using R package "meta," as reported in [45]. The obtained meta-analysis results were depicted in the form of forest plots, also called confidence interval (CI) plots, which present the estimates for the prevalence with confidence intervals for each study. The maximum likelihood estimation (method.tau $=\mathrm{ML})$ method and logit transformation $(\mathrm{sm}=$ PLOGIT) were used for the meta-analysis in this study. The mastitis pathogen prevalence is shown as a square, and the horizontal line extending from either side represents the $\mathrm{CI}$ at a $95 \%$ level for each study considered. The shaded thick red line given below the forest plot is the prediction interval (PI) at the 95\% level. The heterogeneity among the reported studies encompassed in the meta-analysis was determined by Cochran $\mathrm{Q}$ test, and the I-Square, Tau square, $\mathrm{H}$, and $p$ values were obtained. If the studies indicated heterogeneity based on the Cochran $Q(p<0.05)$ and I-square $(>50 \%)$ values, the random effects model (Der Simonion and Laird Method) was used to determine the prevalence estimates. The Cochran $Q$ statistics were determined as per the method reported earlier $[7,8]$ and specify the significance level. The publication bias was assessed by using the Begg and Mazumdar adjusted rank correlation test for the overall prevalence estimates, and it is expressed as a $p$-value. A meta-regression analysis was done to determine the characteristics of the large number of studies that influenced the prevalence estimates. The regression analysis included the model results, the test of moderators, and the tau square, $\mathrm{I}^{2}, \mathrm{H}^{2}$, and $\mathrm{R}^{2}$ values. Based on the $p$-values obtained in the analysis, the potential moderator or modifier of prevalence estimates was determined. The subgroup analysis was done based on various parameters reported in an earlier study [7], with some modifications given below, to understand the heterogeneity among the studies on S, St, and Ec prevalence in the world. A funnel plot, which was used to determine the outliers and to understand the nature of the selected studies, was also used. The prespecified subgroups analyses were (i) overall S, St, and Ec prevalence; (ii) year (1970-2000, 2001-2010, and 2011-2019); (iii) continent (Africa, Asia, Europe, Latin America, North America, and Oceania); (iv) period for continents (before 2011 and after 2011); (v) host species (cattle and buffalo); (vii) method (cultural examination, molecular methods, and other methods); (vii) bacterial species; (viii) type of mastitis (subclinical mastitis and clinical mastitis, mastitis); and ix) country for the world. The overall prevalence estimates for S, St, and Ec based on subgroup analyses were expressed as a percentage along with $\mathrm{CI}$ and PI at the $95 \%$ level.

\section{Conclusions}

In the present study, it was found that the Staphylococcus species is the major mastitis pathogen present in the milk of dairy cattle and buffalo in the world, followed by Streptococcus species and Escherichia coli. Among the bacterial species, S. aureus (25\%), coagulase-negative Staphylococcus species (20\%), Escherichia coli (11\%), St. agalactiae (9\%), and St. uberis (9\%) are the most important mastitis pathogens present in the world. Based on the methods employed for the identification of bacterial species, the molecular methods were found to be more sensitive than culture methods and may be considered in future studies. Further, the $S$ species occurs mostly in subclinical mastitis cases, St occurs in both forms of mastitis, and Ec occurs in clinical mastitis cases. The high-risk countries in the world, global zones, and states in India for mastitis pathogens that were recognized in this study will help policymakers and stakeholders to devise the appropriate preventive measures against these mastitis pathogens. There is an urgent need to improve quality and to avoid bacterial infection in milk by following scientific dairy management practices, clean milk production methods, the regular screening of dairy cattle and buffalo for subclinical mastitis, and proper therapeutic interventions based on antibiotic susceptibility testing. This will help to maintain milk quality, thus preventing public health risks and antimicrobial resistance in human beings. Furthermore, prevalence studies of mastitis 
pathogens are required from the majority of the countries of the world in the future to get more precise estimates.

Supplementary Materials: The following are available online at https: / www.mdpi.com/article/ 10.3390 / pathogens10050545/s1, The supplementary materials for this article can be found online. Supplementary File S1: PRISMA checklist for the systematic review and meta-analysis. Supplementary File S2: Tables of the manuscript. Supplementary File S3: Reference list of the studies included for meta-analysis from the world.

Author Contributions: Conceptualization, P.K.; data curation, P.K. and K.S.J.; formal analysis, K.P.S. and P.K.; methodology, P.K. and K.P.S.; supervision, B.R.S. and R.G.A.; visualization, P.K. and S.S.P.; writing-original draft, P.K.; writing-review and editing, P.K., B.R.S. and R.G.A. All authors have read and agreed to the published version of the manuscript.

Funding: The authors thank profusely for providing necessary support in carrying this research work under Institute research project under Indian Council of Agricultural Research (ICAR), New Delhi, India.

Institutional Review Board Statement: The present study was approved by the Priority-setting, Evaluation and Monitoring cell of ICAR-National Institute of Veterinary Epidemiology and Disease Informatics, Bengaluru, India under the Institute research Project code: IXX13141 and complied with the ethical policies of the journal.

Informed Consent Statement: Not Applicable.

Data Availability Statement: The data presented in this study are available on request from the first author.

Acknowledgments: The authors thank the Indian Council of Agricultural Research (ICAR), New Delhi for providing necessary support in undertaking this research work under the Institute research project.

Conflicts of Interest: The authors declare no conflict of interest.

\section{References}

1. Ruegg, P. A 100-year review: Mastitis detection, management, and prevention. J. Dairy Sci. 2017, 100, 10381-10397. [CrossRef] [PubMed]

2. FAO. Impact of Mastitis in the Small-Scale Dairy Production System; Working Paper No.13; FAO: Rome, Italy, $2014 ;$ pp. 1-34.

3. Costello, S. Consultant Guide to the Economics of Mastitis. 2004. Available online: https:/ /www.smartstock-usa.com (accessed on 10 June 2020).

4. Bansal, B.K.; Gupta, D.K. Economic analysis of bovine mastitis in India and Punjab-A review. Indian J. Dairy Sci. 2009, 62, 337-345.

5. Krishnamoorthy, P.; Suresh, K.P.; Roy, P. Meta-analysis: An innovative tool for estimating the prevalence of livestock diseases. Res. Rev. J. Vet. Sci. Technol. 2020, 9, 4-7.

6. Krishnamoorthy, P.; Suresh, K.P.; Saha, S.; Govindaraj, G.; Shome, B.R.; Roy, P. Meta-analysis of prevalence of subclinical and clinical mastitis, major mastitis pathogens in dairy cattle in India. Int. J. Cur. Microbiol. Appl. Sci. 2017, 6, 1214-1234. [CrossRef]

7. Krishnamoorthy, P.; Ashwini, M.; Suresh, K.P.; Siju, S.J.; Roy, P. Prevalence of Anaplasma species in India and the World in dairy animals: A systematic review and meta-analysis. Res. Vet. Sci. 2019, 123, 159-170. [CrossRef]

8. Krishnamoorthy, P.; Hamsapriya, S.; Ashwini, M.; Patil, S.S.; Roy, P.; Suresh, K.P. Systematic review and meta-analysis of livestock associated-methicillin resistant Staphylococcus aureus (LA-MRSA) prevalence in animals in India. Int. J. Livestock Res. 2019, 9, 179-191. [CrossRef]

9. Walker, E.; Hernandez, A.V.; Kattan, M.W. Meta-analysis: Its strengths and limitations. Clevel. Clin. J. Med. 2008, 75, 431-439. [CrossRef] [PubMed]

10. FAOSTAT. Population of Live Animals in the World-Visualization Tool. 2020. Available online: http://www.fao.org/faostat/ en/\#data/QA/visualize (accessed on 25 August 2020).

11. STATISTA. Milk Production and Consumption Statistics. 2020. Available online: https://www.statista.com/statistics/535806 / consumption-of-fluid-milk-per-capita-worldwide-country/ (accessed on 25 August 2020).

12. BAHS. Basic Animal Husbandry Statistics, Ministry of Fisheries, Animal Husbandry and Dairying; Department of Animal Husbandry and Dairying, Krishi Bhawan: New Delhi, India, 2019; pp. 1-132.

13. Erskine, R.J.; Bartlett, P.C.; VanLente, J.L.; Phipps, C.R. Efficacy of systemic ceftiofur as a therapy for severe clinical mastitis in dairy cattle. J. Dairy Sci. 2002, 85, 2571-2575. [CrossRef] 
14. Quinn, P.J.; Carter, M.E.; Markey, B.K.; Carter, G.R. Clinical Veterinary Microbiology; Harcourt Publishers: Richmond, VA, USA, 2002; pp. 331-344.

15. Hosseinzadeh, S.; Saei, H.D. Staphylococcal species associated with bovine mastitis in the North West of Iran: Emerging of coagulase-negative staphylococci. Int. J. Vet. Sci. Med. 2014, 2, 27-34. [CrossRef]

16. Bakken, G. Subclinical mastitis in Norwegian dairy cows: Prevalence rates and epidemiological assessments. Acta. Agri. Scand. 1981, 31, 273-286. [CrossRef]

17. Daniel, R.C.W.; O’boyle, D.; Marek, M.S.; Frost, A.J. A survey of clinical mastitis in south-east Queensland dairy herds. Aust. Vet. J. 1982, 58, 143-147. [CrossRef]

18. Anderson, K.L.; Lyman, R.; Moury, K.; Ray, D.; Watson, D.W.; Correa, M.T. Molecular epidemiology of Staphylococcus aureus mastitis in dairy heifers. J. Dairy Sci. 2011, 95, 4921-4930. [CrossRef] [PubMed]

19. Bortolami, A.; Gianesella, M.; Fiore, E.; Corro, M.; Catania, S.; Morgante, M. Evaluation of the udder health status in subclinical mastitis affected dairy cows through bacteriological culture, somatic cell count and thermographic imaging. Pol. J. Vet. Sci. 2015, 18, 799-805. [CrossRef]

20. Suleiman, T.S.; Karimuribo, E.D.; Mdegela, R.H. Prevalence of bovine subclinical mastitis and antibiotic susceptibility patterns of major mastitis pathogens isolated in Unguja island of Zanzibar, Tanzania. Trop. Anim. Health Prod. 2018, 50, 259-266. [CrossRef] [PubMed]

21. Vakkamäki, J.; Taponen, S.; Heikkilä, A.M.; Pyörälä, S. Bacteriological etiology and treatment of mastitis in finnish dairy herds. Acta Vet. Scand. 2017, 59, 1-9. [CrossRef] [PubMed]

22. Krishnamoorthy, P.; Satyanarayana, M.L.; Shome, B.R. Coagulase negative staphylococcal species mastitis: Overview. Res. J. Vet. Sci. 2016, 9, 1-10.

23. Bradley, A.J.; Green, M.J. Aetiology of clinical mastitis in six Somerset dairy herds. Vet. Rec. 2001, 148, 683-686. [CrossRef] [PubMed]

24. Dieser, S.A.; Vissio, C.; Lasagno, M.C.; Bogni, C.I.; Larriestra, A.J.; Odierno, L.M. Prevalence of pathogens causing subclinical mastitis in Argentinean dairy herds. Pak. Vet. J. 2014, 34, 124-126. [CrossRef]

25. Petrovski, K.R.; Heuer, C.; Parkinson, T.J.; Williamson, N.B. The incidence and aetiology of clinical bovine mastitis on 14 farms in Northland, New Zealand. N. Z. Vet. J. 2009, 57, 109-115. [CrossRef]

26. Baloch, H.; Rind, T.; Shah, G.; Kalhoro, D.H.; Kalhora, A.B. Study of clinical mastitis in buffaloes caused by Staphylococcal species. Pak. J. Agri. Engg. Vet. Sci. 2013, 29, 88-95.

27. Amosun, E.A.; Ajuwape, A.T.P.; Adetosoye, A.I. Bovine streptococcal mastitis in southwest and northern states of Nigeria. Afr. J. Biomed. Res. 2010, 13, 33-37.

28. Zhang, S.; Piepers, S.; Shan, R.; Cai, L.; Mao, S.; Zou, J.; Ali, T.; De Vliegher, S.; Han, B. Phenotypic and genotypic characterization of antimicrobial resistance profiles in Streptococcus dysgalactiae isolated from bovine clinical mastitis in 5 provinces of China. J. Dairy Sci. 2018, 101, 3344-3355. [CrossRef]

29. Abera, B.; Lemma, D.; Iticha, I. Study of bovine mastitis in Asella government dairy farm of Oromia Regional state, South Eastern Ethiopia. Int. J. Curr. Res. Acad. Rev. 2013, 1, 134-145.

30. Gao, J.; Barkema, H.W.; Zhang, L.; Liu, G.; Deng, Z.; Cai, L.; Shan, R.; Zhang, S.; Zou, J.; Kastelic, J.P.; et al. Incidence of clinical mastitis and distribution of pathogens on large Chinese dairy farms. J. Dairy Sci. 2017, 100, 4797-4806. [CrossRef]

31. Bhanot, V.; Chaudhri, S.S.; Bisla, R.S.; Singh, H. Retrospective study on prevalence and antibiogram of mastitis in cows and buffaloes of eastern Haryana. Indian J. Anim. Res. 2012, 46, 160-163.

32. Tripathi, S.; Arora, N.; Shekhar, S.; Rajora, V.S. Etio-prevalence of subclinical mastitis in crossbred cattle. J. Entomol. Zool. Stud. 2018, 6, 778-780.

33. Islam, N.N.; Farzana, Z.; Chowdhury, A.M.M.A.; Mannan, A.; Kamaruddin, K.M.; Siddiki, A.M.A.M.Z.; Uddin, I. Characterization of bovine subclinical mastitis caused by Staphylococcus aureus in southern Bangladesh by bacteriological and molecular approaches. Asian J. Biol. Sci. 2014, 7, 1-12. [CrossRef]

34. Lakshmi, R.; Jayavardhanan, K. Isolation and identification of major causing bacteria from bovine mastitis. Int. J. Appl. Pure Sci. Agric. 2016, 2, 45-48.

35. Ranjan, R.; Gupta, M.K.; Singh, K.K. Study of bovine mastitis in different climatic conditions in Jharkhand, India. Vet. World 2011, 4, 205-208. [CrossRef]

36. Charaya, G.; Sharma, A.; Kumar, A.; Singh, M.; Goel, P. Pathogens isolated from clinical mastitis in Murrah buffaloes and their antibiogram. Vet. World 2014, 7, 980-985. [CrossRef]

37. Wilson, D.J.; Gonzalez, R.N.; Das, H.H. Bovine mastitis pathogens in New York and Pennsylvania: Prevalence and effects on somatic cell count and milk production. J. Dairy Sci. 1997, 80, 2592-2598. [CrossRef]

38. Breen, J.E.; Green, M.J.; Bradley, A.J. Quarter and cow risk factors associated with the occurrence of clinical mastitis in dairy cows in the United Kingdom. J. Dairy Sci. 2009, 92, 2551-2561. [CrossRef]

39. Kurjogi, M.M.; Kaliwal, B.B. Prevalence and antimicrobial susceptibility of bacteria isolated from bovine mastitis. Adv. Appl. Sci. Res. 2011, 2, 229-235.

40. Harini, H.; Sumathi, B.R. Screening of bovine milk samples for sub-clinical mastitis and antibiogram of bacterial isolates. Vet. World 2011, 4, 358-359. [CrossRef] 
41. Jeykumar, M.; Vinodkumar, G.; Bashir, B.P.; Krovvidi, S. Antibiogram of mastitis pathogens in the milk of crossbred cows in Namakkal district, Tamil Nadu. Vet. World 2013, 6, 354-356. [CrossRef]

42. Joshi, S.; Gokhale, S. Status of mastitis as an emerging disease in improved and periurban dairy farms in India. Ann. N. Y. Acad. Sci. 2006, 1081, 74-83. [CrossRef]

43. Moher, D.; Shamseer, L.; Clarke, M.; Ghersi, D.; Liberati, A.; Petticrew, M.; Shekelle, P.; Stewart, L.A.; Group, P.P. Preferred reporting items for systematic review and meta-analysis protocols (PRISMA-P) 2015 statement. Syst. Rev. 2015, 4, 1-9. [CrossRef] [PubMed]

44. Suresh, K.P.; Patil, S.S.; Hamsapriya, S.; Shinduja, R.; Roy, P.; Amachavadi, R.G. Prevalence of extended-spectrum beta-lactamaseproducing bacteria from animal origin: A systematic review and meta-analysis report from India. PLoS ONE 2019, 14, e0221771. [CrossRef]

45. Schwarzer, G. Meta: An R package for meta-analysis. R. News 2007, 7, 40-45. 